\title{
Le druzisme prémoderne en Syrie : émergence du droit druze et des premières institutions religieuses
}

\author{
Wissam Halabi Halawi \\ University of Exeter \\ whalawi@hotmail.com
}

\section{Résumé}

Les premiers traités du Canon druze dont la rédaction remonte au $\mathrm{V}^{\mathrm{e}} / \mathrm{XI}^{\mathrm{e}}$ siècle jettent les bases d'une doctrine religieuse nouvelle etébauchent succinctement et de manière souvent ambigüe les préceptes moraux, mais aussi juridiques et juridictionnels auxquels les adeptes devaient désormais se soumettre, les lois ( $\left({ }^{a} a r a \bar{a} i\right)$ antérieures ayant été abrogées par la Volonté divine. Les savants druzes du IX $/ \mathrm{XV}^{\mathrm{e}}$ siècle, notamment l'émiral-Sayyid (m. 884/1479) et ses disciples, tentèrent d'expliquercestraités afin d'établirdes principes juridico-religieux adaptésà leurmilieu rural et des règles destinéesà organiserle fonctionnementinterne de la communauté desadeptes. L'historiographie traditionnelle considère toutefois que seulal-Sayyidestl'architecte dece «renouveau druze »; par conséquent, elle lui confère le statut de plus grand réformateur druze de tous les temps et lui attribue un ensemble d'écrits théologiques et juridiques que les initiés observent scrupuleusement depuis lors. Or, une lecture critique de ce corpus inédit datant en partie de la fin du $\mathrm{IX}^{\mathrm{e}} / \mathrm{XV}^{\mathrm{e}}$ siècle révèle que l'émergence des premières institutions druzes, religieuses et judiciaires, ainsi que la théorisation et la systématisation du droit druze sont postérieures à l'action sayyidienne.

\section{Mots clefs}

Druzes, chiisme, ismaélisme, sainteté, Islamic Studies, Islamic Law, fiqh, ta 'wīl, tahkīm, sulh, waqf

* La rédaction de cet article a été effectuée dans le cadre du programme ERC Advanced Award LAWALISI «Law, Authority and Learning in Imami Shi' ite Islam », n ERC 695245. Je remercieMohammadAli Amir-Moezzi de sa constante sollicitudeà monégard et de ses réflexions érudites. Je remercie également Robert Gleave et Élise Voguet de leur disponibilité et pour leurs remarques pertinentes qui ont enrichi ce texte. 



\begin{abstract}
The Epistles of the Druze Canon, written in the 5th/11th century, lay down the foundations for a new religious doctrine, and give a brief and sometimes ambiguous outline of the moral, juridical and judicial precepts to which believers should submit henceforth, all previous legal doctrines ( $\left.\breve{s} a r a{ }^{\prime} i\right)$ having been abrogated by the divine Will. Premodern Druze scholars, especially the Emir al-Sayyid(d. 884/1479) and his disciples, attempted to explain these canonical treatises with the aim of establishing legal and religious principles adapted to their rural milieu and posing rules designed to organise the community. Traditional Druze historiography considers the Emir alSayyid to be the only and greatest Druze reformer of all time, the "architect" of Druze renaissance in sum, and falsely attributes to him a collection of theological and legal writings (the "Great Exegeses") which are scrupulously applied by religious people up to the present day. However, a critical examination of this unpublished corpus (dating from the latter part of the 9th/15th century) shows however that the Druze legal theory, as well as the first religious and judiciary Druze institutions emerged after the death of al-Sayyid.
\end{abstract}

\title{
Keywords
}

Druze, Shi 'ism, Ismailism, Islamic studies, Social history, Islamic law, Fiqh, ta 'wĭl, tahkìm, sulh, waqf

Les études druzes se sont jusqu'à présent principalement intéressées au dogme druze que décrivent les traités du Canon, la Hikma, connus sous le nom d'Épîtres de la Sagesse ou Rasā 'il al-Hikma ${ }^{1}$, ainsi qu' aux circonstances de

1 La Hikma est un recueil de cent onze traités rédigés durant la première moitié du Ve/XIe siècle par trois propagandistes ismaéliens, Ḥamza b. 'Alī, Ismā '̄il al-Tamīmīet Bahā' al-Dīn al-Muqtanā. Pour une édition critique et une traduction annotée des quarante premiers traités, voir Daniel De Smet (éd.), Les Êpitres sacrées des Druzes : Rasā'il al-Hikma, volumes 1 et 2, introduction, édition critique et traduction annotée des traités attribués à Hamza b. 'Alīet Ismā ìl at-Tamīmī, Paris-Louvain-Dudley, Peeters ( Orientalia Lovaniensia Analecta», 168), 2007. Pour une édition de l'ensemble du Canon, voir Ḥamza b. 'Alī, Isma 'īl al-Tamīmī, Bahā' al-Dīn al-Samūqī, Rasā 'il al-Hikma : livre saint des Druzes, éd. Anwar Yāsīn, Liban, Dār li-ağl al-ma 'rifa («Silsilat al-ḥaqīqa l-șa 'ba», 7), 1986, 3 vols; précisons qu'il ne s’agit pas d'une édition critique, le texte ayant été imprimé pour la première fois en 1980, au Liban, sous le pseudonyme d'Anwar Yāsīn et aussitôt contesté par les religieux druzes et interdit par l'État libanais. 
son élaboration dans le Caire fatimide de la première moitié du $\mathrm{V}^{\mathrm{e}} / \mathrm{XI}^{\mathrm{e}}$ siècle $^{2}$. Bien que cette période soit fondatrice pour les Druzes, elle n'en demeure pas moins éphémère à l'échelle de l'histoire du druzisme ${ }^{3}$ et de son évolution socio-culturelle depuis lors et, plus encore, àl'époqueprémoderne. En posantles fondements d'un système religieux nouveau, dont la pierre d'angle est la divinisation du calife al-Ḥākim (r. 386/996-411/1021) ${ }^{4}$, une poignée de propagandistes $(d u$ ' $\bar{a} t)$ ismaéliens ${ }^{5}$ obtinrent, sinon le soutien de ce dernier, du moins sa protection et sa bienveillance, en même temps qu'ils réussirent à agréger un certain nombre d'adeptes à leur mouvement ${ }^{6}$. Leur prédication $\left(d a{ }^{\top} w a\right)$

2 Une littérature historico-idéologique abondante a été produite sur ce sujet par des auteurs druzes à partir notamment du milieu du siècle dernier, dont l'ouvrage de Sami Nasib Makarem, The Druze Faith, Delmar, Caravan Books, 1974; celui d'Amīn Țalī‘, Așl almuwahhidinnal-durūzwa-ușūluhum, Beyrouth, n.d., 1961; etl'article deKais Firro, «The Druze Faith: Origin, Development and Interpretation», Arabica, 58/1 (2011), p. 76-99. La question a également suscité l'intérêt de plusieurs orientalistes et historiens dont les travaux ont largement contribué au développement des études druzes - citons, entre autres, David Bryer, "The Origins of the Druze Religion», Der Islam, 52 (1975), p. 47-83, 239-262 et Der Islam, 53 (1976), p. 5-27 ; Henry Guys, La Nation druse, sa religion, ses mours et son état politique avec la vie de Darazi, de Hamzé et des autres fondateurs de la religion druse, Paris, Challamel Ainé, 1863, réimpr. Amsterdam, Apa-Philo Press, 1979; Philip Khuri Hitti, The Origins of the Druze Peopleand Religion with Extracts from Their Sacred Writings, New York, Columbia University Press («Columbia University Oriental Studies », 28), 1928; Marshall Hodgson, « Al-Darazī and Hamza in the Origin of the Druze Religion », Journal of the American Oriental Society, 82 (1962), p. 5-20; Antoine-Isaac Silvestre de Sacy, Exposéde la religion des Druses tirédes livres religieuxdecettesecte, etprécédéd'une introductionet de la Viedukhalife Hakem-biamr-Allah, Paris, Imprimerie Royale, 1838, réimpr. Cambridge, 2013.

3 Par «druzisme » nous entendons « tawhĭd druze», autrement dit la doctrine du tawhìd ou de l'«unicité» de Dieu telle qu'elle est développée par les auteurs druzes dans les traités canoniques et, plus tard, dans les textes exégétiques et juridico-théologiques. Le druzisme peut également renvoyer à la dimension culturelle de cette doctrine au sein de la société.

4 Sur le statut d'al-Hāāim dans la doctrine druze, voir De Smet, Épîtres sacrées, p. 40-42, 6064. De nombreuses études existent sur le règne d'al-Ḥākim; voir, en dernière instance, Paul Walker, Caliph of Cairo: Al-Hakim bi-Amr Allah, 996-1021, Le Caire, American University in Cairo Press, 2009.

5 Sur la confusion entre ces propagandistes dans les chroniques arabes médiévales, voir Wissam H. Halawi, «Les Druzes dans les chroniques arabes médiévales : unenarrationéclatée», Studia Islamica, 104-105 (2007), en particulier p. 130-131.

6 Bien que le nombre d'individus ayant rejoint le mouvement druze au Caire soit impossible à déterminer, les auteurs arabes médiévaux dont certains sont contemporains de la naissance du mouvement emploient le terme al-daraziyya pour désigner ce groupe d'adeptes (al-Anțākī, Histoire de Yahyā Ibn Sa '̄̀d d'Antioche, éd. Ignace Kratchkovsky, trad. Françoise Micheau et Gérard Troupeau, Turnhout, Brepols [ « Patrologia Orientalis», 47/4], 1997, p. 428-429), ou encore relatent que, lors de certaines processions, al-Hākim fut acclamé par « un groupe d'ignorants qui lui criait: Toi,l'Unique etl'Un, [tu es] celui qui donne la vie et la mort»(al-Dahabī,Ta'rīhal-islāmwa-wafiyyātal-mašāhirwa-l-a lām,éd. 'Umar 'Abdal-Salām 
fut d'abord publique durant un laps de temps assez court, de 408/1017-1019 à 411/1021, avantd'êtrerendue secrètejusqu'en434/1042-1043, dateàlaquelle elle fut définitivement close. Les décennies qui s'ensuivirent furent marquées par la disparition du druzisme en Égypte et son implantation dans les montagnes syriennes où la da 'wa avait été favorablement accueillie au sein des élites autochtones ${ }^{7}$. Certaines de ces localités demeurent jusqu'à nos jours les principaux foyers des communautés druzes du Moyen-Orient, à l'instar du Ğabal al-Summāqprès d'Alep, du Wādīl-Taym au sud duLiban actuel et de multiples villages dans la région du Ġarb et du Šūf au sud-est de Beyrouth. Il n'est donc pas étonnant que le druzisme se soit développé en particulier dans ces régions, en s'adaptant aux réalités sociales et politiques locales.

Nonobstantl'importance delapériode syrienne dans l'histoire du druzisme médiéval et prémoderne, les chercheurs ne lui ont attaché que peu d'intérêt en raison sans doute de la rareté des sources ou, plus précisément, de leur inaccessibilité. En effet, mis à part une copie partielle de la Hikma datant probablement de la première moitié du VIIe/XIIIe siècle ${ }^{8}$, nous ne disposons pour le moment d'aucun autre texte druze contemporain des siècles obscurs ou méconnus qui séparent la fermeture de la da 'wa de la seconde moitié du $\mathrm{IXe} / \mathrm{XVe}$ siècle. Les chroniqueurs arabes médiévaux ne se sont pas non plus intéressés aux membres des communautés druzes de Syrie, lesquels habitaient dans des villages périphériques et n'avaient, à leurs yeux, aucun rôle politique ou social significatif. De plus, la chronique d'Ibn Yahya $\bar{a}^{-9}$ et celle d'Ibn Sibāt ${ }^{10}$, produites dans lemilieu druzeduĠarb respectivement vers la fin delapremière moitié du IXe/XVe siècle et au début du siècle suivant, ont servi les historiens druzes notamment libanais dans l'élaboration d'un récit communautariste et

Tadmurī, Beyrouth, Dār al-kitāb al- 'arabī, 2003, tomes années 401-420, p. 28, 247 ; alDawādārī, Kanz al-durar wa-ğāmi 'al-ğurar, VI, al-Durra al-muḍ̂̀'a fì aḩbār al-dawla l-fățimiyya, éd. Șalāḥ al-Dīn Munağğid, Le Caire, al-Ma had al-almānī li-l-ātār, 1961, p. 259).

7 Pour les traités que le propagandiste al-Muqtanā, chef de la da $w a$ après la disparition d'al-Ḥākim et deḤamza en 411/1021, adresse aux habitants deplusieurs localités rurales du Bilād al-Šām, notamment les chefs de trois familles originaires du Ġarb et du Wādī 1-Taym, voir Rasā' il al-Hikma, II, p. 380, III, p. 758-760, 762-763, 776, 793-796.

8 De Smet, Épitres sacrées, p. 115-116.

9 Șāliḥ b. Yahyā, Ta'rīhnBayrūtwa-huwa ahbāral-salafmind durriyyatBuhtur 'Alīamìral-Ġarb bi-Bayrūt/Ta' rīhn Bayrūt : récits des anciens de la famille de Buhtur b. 'Alī, émir du Gharb deBeyrouth, éd. Francis Hours et Kamal Salibi, Beyrouth, Darel-Mashreq( «Recherches publiées sous la direction de l'Institut de lettres orientales de Bayrouth. Séries 4, Histoire et sociologie du Proche-Orient », 35), 1969.

10 Aḥmad b. Sibāt, Sidq al-ah̆bār : ta'rī̄n Ibn Sibāt, éd. 'Umar 'Abd al-Salām Tadmurī, Tripoli (Liban), Jarrous Press, 1993. 
idéalisé ${ }^{11}$. Ces deux chroniques ont par ailleurs été exploitées par les spécialistes de l'époque mamelouke ${ }^{12}$, étant donné qu'elles rapportent les hauts faits des émirs druzes issus des Banū Buhtur qui ont été admis comme officiers de la halqa à partir de la fin du $\mathrm{VII}^{\mathrm{e}} / \mathrm{XIII}^{\mathrm{e}}$ siècle $^{13}$. Quant aux textes rédigés par les savants druzes durant la seconde moitié du $\mathrm{IX}^{\mathrm{e}} / \mathrm{XV}^{\mathrm{e}}$ siècle et la première moitié $\mathrm{duX} / \mathrm{XVI}^{\mathrm{e}}$ siècle, ils demeurent soigneusement gardés secrets par les chefs religieux et, par conséquent, sont inaccessibles aux chercheurs. Ce corpus inédit composé de deux textes à caractère hagiographique, d'un ouvrage de théologie et de deux traités juridiques est pourtant essentiel pour l'étude de l'histoire du druzisme prémoderne.

Dans le cadre de mon travail de doctorat ${ }^{14}$, $\mathrm{j}$ 'ai réussi à reconstituer une grande partie de cette littérature inédite à partir de fragments manuscrits conservés essentiellement dans les bibliothèques européennes et libanaises ${ }^{15}$. Cet article est une tentative pour poser les premiers jalons pour une nouvelle lecture de l'histoire du druzisme prémoderne, en s'attachant à replacer la genèse, la production et la réception de ce corpus hagiographique et juridique dans le contexte social et politique du Bilād al-Šām aux IX $/ \mathrm{XV}^{\mathrm{e}}$ et $\mathrm{X}^{\mathrm{e}} / \mathrm{XVI}^{\mathrm{e}}$ siècles. C'est selon cette logique que j'ai construit le plan de l'analyse: d'abord, déconstruire la figure mythifiée du célèbre maître spirituel, Ğamāl al-Dīn 'Abd Allāh (m. 884/1479), connu sous le nom d'al-Sayyid, en confrontant les hagiographies sayyidiennes aux chroniques locales et, partant, étudier l'évolution de ses représentations sur la longue durée et tenter de mieux comprendre sa vie et son action en les recontextualisant; puis reconstituer le groupe de disciples qui appartenaient à son école théologique et juridique, et qui représentaient le milieu dans lequel ont été rédigés les deux premiers traités de droit druze; et, enfin, analyserl'émergence des premières institutions druzes et leur

11 Voir, entre autres, Sami Makarem, Lubnānfì 'ahd al-umarā' al-tanūhiyyīn [=Lebanon under the Tanūkhid Emirs], Beyrouth, Dar Sader, 2000.

12 À titre d'exemple, sur les précisions qu'Ibn Yahyā rapporte sur le rawk al-nāṣirī, voir Anne Troadec, Les Mamelouks dansl'espacesyrien: stratégiesdedomination etrésistances (658/1260-741/1341), thèse de doctorat préparée sous la direction de Denise Aigle, École Pratique des Hautes Études, 2014, p. 359-364.

13 Ibn Yahyā, Ta'rīh Bayrüt, p. 84-85.

14 Wissam H. Halawi,LedruzismeauIXe/XVesiècle:entrehagiographiesayyidienneetréalités sociales, thèse de doctorat préparée sous la direction de Daniel De Smet et Françoise Micheau, Université Paris 1 Panthéon-Sorbonne, 2016.

15 En Europe : la Bibliothèque nationale de France, la Staatsbibliothek de Berlin et la Staatsbibliothek de Munich; au Liban : la Bibliothèque Orientale de l'Université SaintJoseph, les bibliothèques de l'Université Américaine de Beyrouth et de l'Université SaintEsprit de Kaslik, et, enfin, le département des Manuscrits à l’Université de Balamand. 
rapport au pouvoir politiquelocal, notamment celui des Banūl-Ḥusayn, émirs du Ġarb.

\section{1- Action de l'émir al-Sayyid, uneillustration d'un druzismearchaïque}

Pour étudier l'histoire du druzisme à l'époque médiévale, le chercheur se heurte à deux difficultés majeures : la première, on l'a vu, relève de la rareté des sources; la seconde est la construction historiographiqueàlaquelle se sont livrés les auteurs druzes actuels et qui a fini par devenir le récit communautaire officiel. Ces auteurs, conscients du «trou noir ${ }^{16}$ que représente la période prémoderne dans leur passé et peu familiers de la critique historique, narrent des anecdotes transmises oralement depuis des générations au sein des communautés druzes en leur donnant valeur de vérité incontestable ${ }^{17}$; ils se fondent également sur des hagiographies de chefs spirituels, dont certaines ont été rédigées quelques décennies auparavant ${ }^{18}$. En résulte un discours idéologique et linéaire de l'histoire druze ${ }^{19}$.

Au cœur de cette fiction historique se trouve la figure de l'émir al-Sayyid. En effet, celui-ci y est présenté comme le trait d'union entre la da 'wa druze et le druzisme contemporain. En d'autres termes, il serait l'homme providentiel qui aurait révélé le sens caché de la Hikma et qui aurait en plus élaboré un système juridique d'inspiration religieuse, la tradition druze considérant que

$16 \quad$ J'emprunte cette expression à Daniel De Smet, Épîtres sacrées, p. 86.

17 Ces anecdotes ont dernièrement été collectées dans un recueil de traditions par Farḥān al-'Arīụī, Kitāb manāqibal-a yān, Aley, Madrasat al-išrāq, 1994-2011,3 vols.

18 Voir, entre autres, 'Ādil 'Abd al-Șamad, Sirrat al-Šayh Muhammad Qāsim 'Abdal-Șamad, Liban, 2009; 'Abd al-Wahhāb Bašīr Abū Fahrr (éd.), Sirrat Sayyidināal-Šayh Abū Hasan Ibrāhīmal-hiğrī, s.l., Ma raḍ al-Šūf al-dā' im, nd.; 'Ārif Abū Šaqrā, Talātat 'ulamā' min šuyūh Bañ̄ Ma 'rüf: ši 'ruhum, ädābuhum, tașawwufuhum [= Three Druse sages: short biographies of threelebanesepoets with selections from their works revealingmoslemunitarian tendenciesofmedievaldruzesufism], Liban, 19822; Sami Makarem, al-Šayh 'AlīFārisradiya Llāh 'anhu: wal̄ min al-qarn al-țānī 'ašar li-l-hiğra al-tāmin 'ašar li-l-mīlād, Muhtāra, alMarkazal-wațanīli-l-ma 'ūmātwa-l-dirāsāt-al-Mağlisal-durzīli-l-buhūțwa-l-inmā' ,1990; 'Abd Allāh Salīm Ṭarīf, Sìratsayyidināl-šayh AmīnṬarîfwa-sīrathayātsayyidinā l-marḥūm al-šayh 'Alī Fāris, Jérusalem, 1987.

19 Voir Nejla Abu-Izzeddin, The Druzes: A new study of their history, faith and society, Leyde, E.J.Brill, 1984;Nassim Dana, The DruzeintheMiddleEast:TheirFaith,Leadership,Identity and Status, Brighton-Portland, Sussex Academic Press, 2003 ; Kais Firro, A History of the Druzes, Leiden, Brill(«Handbuch der Orientalistik. 1, Der Nahe und der mittlere Osten, Ergänzungsband», 9), 1992, en particulier chap. I (consacré à la période médiévale et prémoderne); Sami Swayd, Historical Dictionary of the Druzes, Lanham-Toronto-Oxford, Scarecrow Press («Historical Dictionaries of Peoples and Cultures», 3), 2006. 
les adeptes s'étaient égarés après la clôture de la prédication ${ }^{20}$. D'aucuns vont jusqu'à écrire qu'al-Sayyid serait la réincarnation de Hamza ${ }^{21}$, voire que son action aurait été annoncée dans le Canon ${ }^{22}$ ! Cette vision anhistorique qui s'inscrit dans un contexte socioculturel de production et de réception marqué par le communautarisme a fortement influencé les études druzes, si bien qu'elle a parfois été adoptée par des historiens extérieurs à la communauté druze ${ }^{23}$.

Toutefois, la figuremythifiée d'al-Sayyid n'a pasété forgée de toutes pièces par les auteurs druzes contemporains, puisqu'elle trouve ses racines dans la littérature prémoderne à caractère hagiographique, notamment les récits ha-

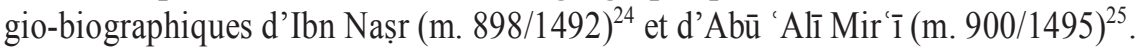
Alors qu'ils manifestent la même intention de dépeindre la grandeur de leur maître, ces deux auteurs se distinguent tant par leur parcours que par le contenu de leur discours : Ibn Nașr, un initié de haut rang ${ }^{26}$, emploie une écriture absconse et ésotérique, évoque les événements de son époque de manière générale et teinte son récit d'une vision apocalyptique et eschatologique; Mir 'ī, d'unniveaud'éducationpeuélevé, commeil le ditlui-même, s'attacheàrelater par des mots simples, sans prétention littéraire, les épisodes ayant marqué la vie d'al-Sayyid. Il convient ici de préciser que l'un comme l'autre ont connu l'émiral-Sayyid à une période avancée dans sa vie et, par conséquent, ignorent

20 À titre d'exemple, voir Sami Abū Šaqrā, al-Tawhīd al-durzī fì maḍūnihi l-insānī, Ammațūr, Maktabat al-anwār, 1984, en particulier p. 21 ; Fu' ād Abū Zakī, al-Amīr alSayyid Ǧamālal-Dīn 'AbdAllāhal-Tannūhī: sìratuhu wa-adabuhu, Liban, 1997; Makarem, Lubnān, notamment p. 193.

21 Hamza est le fondateur de la doctrine druze (voirsupran. 1). Nayla Kaidbey, «Al-Sayyid Jamal al-Din al-Tanukhi as a Druze Reformer », dans The Druze: Realities \& perceptions, éd. Kamal Salibi, Londres, Druze Heritage Foundation, 2005, p. 43-59(notammentp. 47).

22 Kais Firro, «al-Tanūkh̄̄ Djamāl al-Dīn 'Abd Allāh», EI2.

23 Voir Joseph Azzi, Entre la raison et le prophète: essai sur la religion des Druzes, Paris, Jacques Bertoin («Questions d'Orient»), 1992,p. 25 ; Marie Dupont, Les Druzes, Turnhout, Brepols («Fils d'Abraham»), 1994, p. 31 ; Fuad Khuri, Being a druze, Londres, Druze Heritage Foundation, 2004, p. 30; Kamal Salibi, «Le Liban sous les Mamelouks», dans Histoire du Liban des origines au XXe siècle, dir. Boutros Dib, Paris, Philippe Rey, 2006, p. 292-293.

24 Pourunetraduction annotée de cetexte, voirWissam H. Halawi, «Le Kitāb Durratal-tāğ wa-sullamal-mi 'rāğ d'Ibn Nașr : un éloge de Ǧamāl al-Dīn 'Abd Allāh al-Tanūhī (820/1417884/1479)», Arabica, 58/1 (2011), p. 128-164.

25 Pour une édition critique de ce texte, voir Halawi, Le druzisme au IXe/XVe siècle, p. 565-577.

26 Nous appelons «initié» tout adepte druze faisant partie de l'élite religieuse druze, le druzisme étant une religion initiatique. Au sein de ce groupe, les initiés se distinguent par leur degré d'initiation; ainsi, certains sont considérés comme des jeunes initiés, d'autres comme des initiés de rang supérieur ou de haut rang. 
ou probablement se désintéressent du cheminement qui l'a conduit à promulguer un enseignementspirituel.

Au niveau méthodologique, les récentes études de l'histoire de la sainteté en Islam nous autorisent à considérer l'hagiographie sayyidienne comme le reflet à la fois d'un idéal et de la réalité d'un milieu ${ }^{27}$. Le saint homme, voire le saint patron, que décrivent Ibn Nașr et Mir '̄ tire ainsi son individuation des croyances et pratiques locales, mais incarneégalement un modèle culturel qui lui préexiste ${ }^{28}$. Les vertus morales et physiques de leur héros, sa prédestinée, son ascèse, sa piété, sa charité, son indigence et son équité témoignent donc aussi bien de la popularité du personnage historique que du processus de sa mythification dès le lendemain de sa mort. Un examen minutieux du texte d'Ibn Nașr montre également que l'auteur met dans la bouche de son maître des exhortations qui reflètent ses préoccupations personnelles du moment ${ }^{29}$. Ces textes hagiographiques doivent toutefois être analysés à la lumière des indications que fournitla littérature narrative locale. Intéressons-nous d'abordà la chronique d'Ibn Sibāț (m. ca 926/1520) qu'il rédige dans la continuité de celle d'Ibn Yaḥyā afin de décrire l'autorité, dans le Ġarb, des émirs issus des Banū 1-Husayn. Ainsi, proche du pouvoir local et ne faisant pas partie du groupe des initiés druzes, Ibn Sibāṭ porte un regard nouveau sur l'action de l'émir al-Sayyid dans une longue notice biographique extrêmementélogieuse et rédigeunenotice nécrologique sur chacun de ses élèves ayant occupé un rang élevé au sein du groupe30. De son côté, Ibn Yahyaā (m.ca 840/1437), tout commeal-Sayyid, est un émir appartenant aux Banū 1-Husayn. Sa chronique est un récit tellement détaillé de son milieu qu'elle est indispensable pour analyser le contexte

27 Voir, entre autres, Denise Aigle (dir.), Saints Orientaux, Paris, Éditions de Brocard («Hagiographies médiévales comparées », 1), 1995 ; ead., Miracle et Karāma, Turnhout, Brepols («Bibliothèque de l’École des Hautes Études Section des sciences religieuses», 109; «Hagiographies médiévales comparées », 2), 2000; Nelly Amri et Denis Gril(dir.), Saint et sainteté dans le christianisme et l'islam : le regard des sciences de l'homme, ParisAix-en-Provence, Maisonneuve \& Larose-Maison méditerranéenne des sciences de l'homme («L'atelierméditerranéen»), 2007; Rachida Chih et Denis Gril (éds), Le saint et son milieu ou comment lire les sources hagiographiques, Le Caire, Institut Français d'Archéologie Orientale («Cahiers des Annales islamologiques », 19), 2000; Josef W. Meri, The Cult of Saints among Muslims and Jews in Medieval Syria, Oxford-New York, Oxford University Press («Oxford Oriental Monographs »), 2002.

28 À ce sujet, voir Wissam $H$. Halawi, «La réforme druze dans les montagnes syriennes au IXe/XVe siècle », Revue des Mondes Musulmans et de la Méditerranée, 135 (2014), p. 99-130. Pourun exposé plus complet, voir Halawi,LedruzismeauIXe/XVe siècle, p. 163-187.

29 Halawi, «Kitāb Durratal-tā̆ğ», p. 154-157. Pourune analyse de ce discours, voir Halawi, Le druzisme au IXe/XVe siècle, p. 271-277.

30 Ibn Sibāț, Ta'rīh, p. 896-935. 


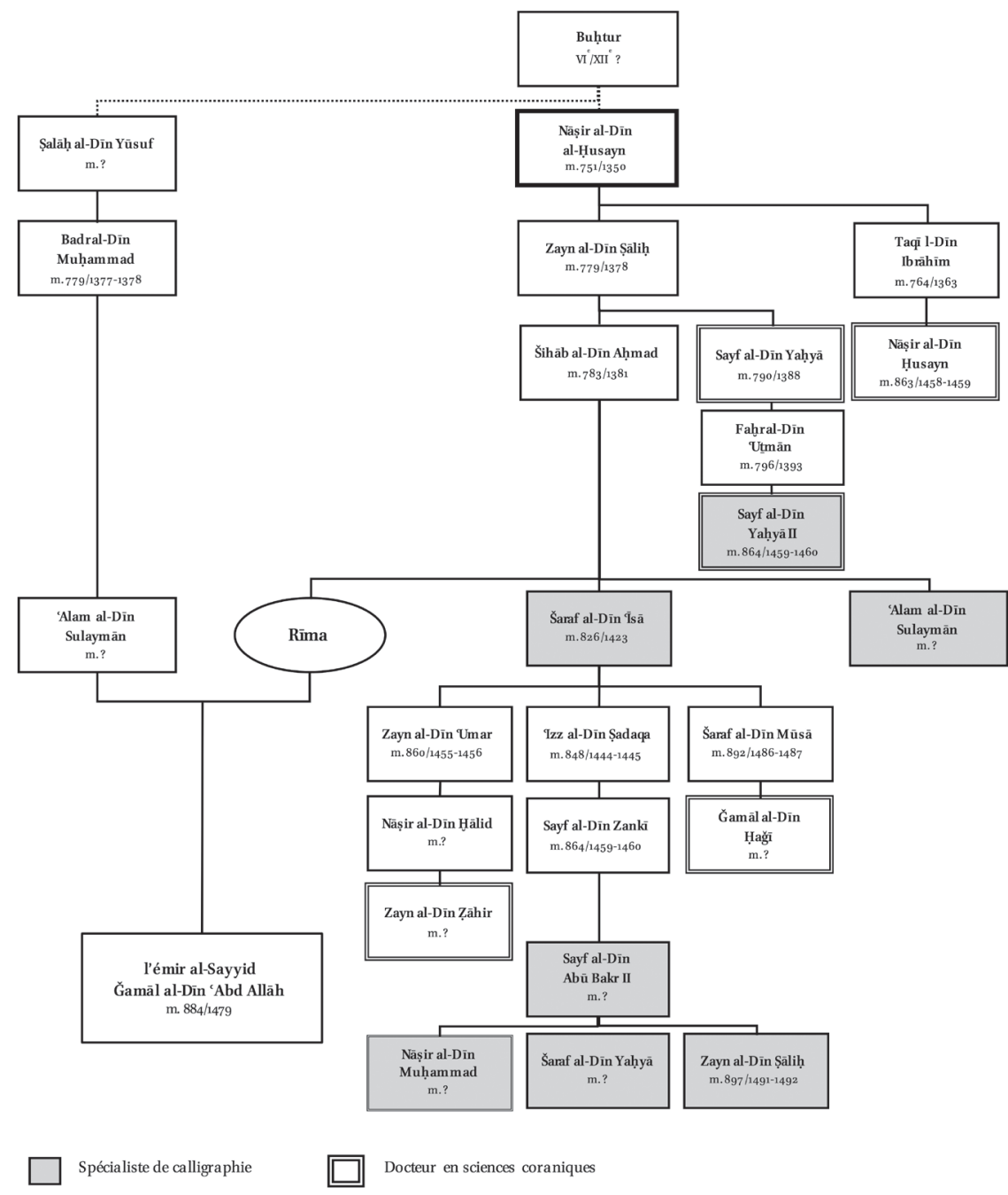

figure 1 Les Banūl-Ḥusayn.

Sources : Ibn Sibāț, Ta 'rīḥ ; Ibn Yaḥyā, Ta 'rīh Bayrūt

familial et politique dans lequel l'émir al-Sayyid a vécu - quand bien même l'auteur ne le mentionne pas dans son texte.

Ainsi,confronterles textes hagiographiques àla littératurenarrativepermet de déconstruire les figures et les Vitae d'al-Sayyid afin de mieux comprendre sa vie et son action dans la région rurale du Ġarb. Contentons-nous ici de trois thèmes significatifs qui offrent une vision précise du modèle d'homme idéal selon lequel les hagiographes ont construit la figure de sainteté d'al-Sayyid et qui permettent d'élucider sa contribution à l'évolution du druzisme: d'abord, 
son milieu familial, puis son magistère dans la science à la fois du $t a$ 'wìl et du fiqh; et, enfin, son rôle d'arbitre au sein de la société.

Alors que les hagio-biographes font une description mythifiée du père d'alSayyid $^{31}$, Sulaymān, celui-ci est décrit laconiquement par son contemporain Ibn Yahya ${ }^{32}$ - qui, rappelons-le, rédige sa chronique à une période antérieure à celle où le « sayyidisme » ${ }^{33}$ avait acquis une certaine popularité. De surcroît, à l'exception de son arrière-grand-père paternel ayant connu une courte notoriété en tant que simple dayyin (religieux) ${ }^{34}$, les autres parents agnatiques de l'émir sont pratiquement ignorés à la fois par les hagiographes et les chroniqueurs ${ }^{35}$.

Toutefois, l'émir al-Sayyid appartient, de par sa mère, à la prestigieuse familledesBanūl-Ḥusayn, branche des BanūBuhturqui s'estinstalléeà 'Abayy, village du Ġarb, vers le début du VIIe/XIVe siècle. Si le fondateur éponyme de la maison (bayt) est un certain Buhtur, son pilier et homme fort est résolument Nāṣir al-Dīnal-Husayn (m. 751/1350) lequel, grâceà des stratégies d'alliances matrimoniales et politiques, s'érigea en autorité sociale locale et gagna la confiance du pouvoir central ${ }^{36}$. Ses descendants lui succédèrent à la tête de la famille jusqu'au début du $\mathrm{X}^{\mathrm{e}} / \mathrm{XVI}^{\mathrm{e}}$ siècle; en font partie deux personnages ayantjouéun rôle clédans lavie del'émiral-Sayyid, samère Rīmaetson maître l'émir Sayf al-Dīn Yahyā (m. 864/1459-1460).

Rīma, la fille de Šihāb al-Dīn b. Zayn al-Dīn b. Nāṣir al-Dīn al-Ḥusayn, est issue de la branche principale des Banūl-Husayn (al-Husayn > Zayn al-Dīn > Šihāb al-Dīn) ou, plus justement, de celle dont les membres détenaient les plus grands $i q t \bar{a}$ 's (concessions foncières) de la région et, qui plus est, occupaient les plus hauts rangs dans la hiérarchie politique locale. Cette dynastie fondée par al-Husayn faisait partie de la noblesse rurale du Ġarb, comme l'atteste le titre d'amīr (émir) attribué à ses représentants, un titre honorifique qui n'était pas uniquement porté par ceux parmi les Banū l-Husayn qui étaient officiers mamelouks. En plus de la noblesse utérine, al-Sayyid jouit d'un entourage familial composé non seulement d'hommes de pouvoir, mais aussi de savants en sciences religieuses, dont notamment Sayf al-Dīn Yahyaā. Dans sa

31 Halawi, «Kitāb Durrat al-tāğ », p. 139-141.

32 Ibn Yahyā, Ta'rīh Bayrūt, p. 223.

33 Nous appelons « sayyidisme» l'enseignement moral et religieux attribué à l'émir alSayyid, le «druzisme sayyidien» devant être distingué du druzisme dans sa globalité. Ce terme sera égalementutilisé pour désignerl'écolejuridique druze, dontle fondateuréponyme est al-Sayyid.

34 Ibn Yahyā, Ta'rīh Bayrūt, p. 146.

35 Ibn Sibāt, Ta'rīh p. p70-871.

36 Voir Halawi, Le druzisme au IXe/XVe siècle, p. 461-487. 
chronique, Ibn Sibāt fournit des indications permettant de penser que ce dernier joua un rôle de premier ordre dans la vie d'al-Sayyid en lui transmettant un savoir livresque et en lui léguant l'ensemble de ses biens constitués waqf ${ }^{37}$. Sayf al-Dīn fut sans doute le maître d'al-Sayyid. Pourtant, l'hagiographie sayyidienne aussi bien que l'historiographie druze ignorent ce personnage, voire l'occultent, afin de garder d'al-Sayyid l'image d'un saint homme dépourvu de toute richesse matérielle, dont l'âme fut éclairée par Dieu.

Cela nous amène à la supériorité savante d'al-Sayyid et au magistère scientifique $^{38}$ qu'il exerçait sur ses contemporains. En ne lui reconnaissant aucun maitre spirituel, ses disciples-biographes, suivis par les auteurs traditionnels actuels, lui confèrent une « connaissance innée » (ma'rifa) de Dieu l'ayant conduit à expliquer le sens caché de la Hikma et à en extraire les règles juridiques druzes. Son magistère dans la science du ta 'wīl (interprétation ésotérique), rendu dans les sources de première main par 'ilm ou « science ésotérique », est donc considéré comme un miracle en soi $^{39}$; par conséquent, aucune action thaumaturgique ne lui était nécessaire pour affirmer sa sainteté aux yeux des adeptes. Or, le druzisme est une religion initiatique qui se construisit dans le sillage du chiisme ismaélien, si bien que le bāțin (sens caché) est nécessairement transmis de maître à élève en respectant le principe de transcendance ${ }^{40}$. Ainsi, la ma 'rifa d'al-Sayyid, symbole sans doute de sa piété, ne pouvait pas le conduire au 'ilm qu'il aurait acquis auprès d'un ou plusieurs savants druzes ayant une grande maîtrise des arcanes des traités canoniques. Cela n'enlève rien à l'originalité de l'enseignement qu'il aurait prodigué desonvivant, puisque sesopposantsl'accusèrentalors de vouloir instaurerdes

37 Ibn Sibāț, Ta'rīh, p. 805-807, 837, 847-848.

38 Cf. Nelly Amri, «Magistère scientifique, ascèse et patronage rural: les figures du saint homme à Kairouan du VIIe/XIIIe au IXe/XVe siècle, d'après le dictionnaire biographique d'Ibn Nâjî », dans Saint et sainteté dans le christianisme et l'islam, dir. Nelly Amri et Denis Gril, Paris-Aix-en-Provence, Maisonneuve \& Larose-Maison méditerranéenne des sciences de l'homme («L'atelier méditerranéen»), 2007, p. 167-230.

39 Pour la description qu'en fait Ibn Nașr, voir Halawi, «Kitāb Durrat al-tāğ », p. 143-144.

40 Le principe de transcendance ( $\operatorname{tanz\overline {\imath }} h$ ) est étayé dans les ușūl al-dīn druzes où il apparaît comme inhérent au principe de wuğūd ou «manifestation physique du nāsüt (forme humaine de Dieu) sur terre», lequel est à la fois la seule source de 'ilm et la preuve envoyée parl'Ineffable aux humains : Šarh al-Kašf, MS Berlin, Staatsbibliothek, Or. Quart, fol. 2r-3r. Pour une excellente synthèse sur la différence entre l'immanence qui caractérise l'accès au bātin des maîtres soufis et la transcendance dans la dogmatique des docteurs chiites, voir Daniel De Smet, «Zâhir et bâtin », dans Dictionnaire critique de l'ésotérisme, dir. Jean Servier, Paris, Presses Universitaires de France, 1998, p. 1387-1392. 
« impératifs (awāmir) nouveaux $»^{41}$, autrement dit des innovations (bida , sing. bid ' $a$ ) en matière religieuse mais probablement aussi juridique.

L'émir al-Sayyid est également décrit par ses contemporains comme un faqīh docte en sciences du Coran et du hadith ${ }^{42}$, même si cette part de connaissance occupe une place moins importante dans le discours de ses disciples dont le fort attachement à la science ésotérique est indéniable - que dans celui d'IbnSibāṭui était, on l'a vu, extérieur au cercle des initiés. Al-Sayyidétait-il pour autant reconnu par les oulémas comme un spécialiste du fiqh? Aurait-il suivi des cours lui permettant d'approfondir ses connaissances en la matière? Le terme fiqh désigne-t-il dans les sources druzes le droit musulman dans sa globalité ou bien une école juridique en particulier? Nos sources sont en effet ambiguës sur ces points. Alors que Mir '̄i indique qu'al-Sayyid auraitétudiéle Coran lors de son séjour à Damas ${ }^{43}$, Ibn Nașr écrit vers la fin de son éloge:

[L'émir al-Sayyid] employa ses prédications pour éveiller et donner l'exemple. Il abreuval'excès de soifet fit dépérir le lien del'aveuglement. Il comblales gens parla Sagesse splendide (al-Hikmal-bāhira), prédicatrice et manifeste. Ensuite, il se dressa et fit asseoir son autorité. Il réunit ses grandes assemblées (mağălisuhu), célèbres, [durant lesquelles] il étala les sciences ( 'ulüm) avancées et leurs explications éclairantes. Il fit partie des transmetteurs du hadith (muhaddițūn) et des maîtres de [transmission] de la mémoire. Il approuvait l'islam [en tant que] lois et lumières. Il dressa le flambeau de la vérité (haqq) et possédait des dons (karāmāt) et des mystères (asrārr). Ses marques d'élévation (a lām) furent dressées et ses jugements apparurent. Il satisfit les querelleurs en réprimant les tyrans et en rendant justice aux opprimés. Il récita les versets [coraniques] etéclaircit [leurs] sens. Il maîtrisait leniveau le plus poussé des sciences ( 'ulüm) avancées. Il éloigna les gens du malheur ${ }^{44}$.

Bien qu' aucune mention du livre saint de la Hikma ou de la science ésotérique ne figure dans son texte, Ibn Sibāṭ, à l'instar d'Ibn Nașr, s'efforce-t-il de démontrer qu'al-Sayyid était un grand $f a q i ̄ h$, admis et respecté par ses pairs :

$41 \quad$ Halawi, «Kitāb Durrat al-tāğ », p. 146.

42 Notamment dans le discours d'Ibn Nașret d'Ibn Sibāṭ, alors que Mir 'īest plus réservé sur la question (pour ces trois versions différentes, voir notes suivantes).

43 Mir'̄i, MS Berlin, Staatsbibliothek, Ldbg 210, fol. $247 \mathrm{v}$; Halawi, Le druzisme au IXe/XVe siècle, p. 569 (éd.).

44 Halawi, «Kitāb Durrat al-tāğ », p. 157. 
Il se nourrissait du livre de Dieu [le Coran] vénéré, saint et pur, qu'il étudiait et récitait par cœur. Il continua de l'étudier jusqu'à graver ses chapitres dans son cœur. [...] Il atteignit un tel degré d'étude qu'il devint connu et reconnu. [...] Il développa les sciences du fiqh et du hadi $\underline{i},[\ldots]$ ordonna avec vigueur la mémorisation du [livre] vénéré et son apprentissage par les jeunes et par les plus âgés. [...] Dans les villages, ilordonna la construction demosquées, [...] établitdes fondations pieuses (awqāf), $[\ldots]$ attira les juristes $\left(f u q a h \bar{a}{ }^{\prime}\right)$ vers les contrées et instaura le sermon du vendredi. [...] Il suivaitles traces des fuqaha ' 'et des 'ulam $\bar{a}$ ', s' informait sur les amis de Dieu (awliy $\left.\bar{a}^{\prime}\right)$ et sur les ascètes $(z u h h \bar{a} d)$. [...] Il réunit les exégèses ( $\check{s} u r u ̄ h a ̄ t)$ et les explications (tafāsìr) du Saint Coran [...], ainsi que [les récits] sur la vie des prophètes (ahbār al-anbiy $\left.\bar{a}^{\prime}\right)$, [ceux] sur la vie du prophète [de l'islam] (al-ahbāral-nabawiyya), les livres de fiqh [...]. Il simplifiait un savoirétendu, en clarifiant ses difficultés et ses vastes sujets, lisait le livre saint et ses explications, discutait de la science du fiqh et du hadi $\underline{\underline{t}}[\ldots]^{45}$.

À en croire ces deux récits, l'émir al-Sayyid aurait été un faqīh et un 'ālim de renom, mais aussi un transmetteur du hadith. Il aurait de surcroît œuvré à instaurer l'apprentissage du Coran dans sa contrée, voireàl'islamiser. Or, la chronique d'Ibn Yahyyā ne manque pas d'exemples d'émirs issus des Banū l-Ḥusayn et connus pour avoir été des docteurs en sciences coraniques (voir fig. 1). En outre, pour apprendre et expliquer les traités de la Hikma, qui sont émaillés de citations coraniques ${ }^{46}$, al-Sayyid devait acquérir au préalable une connaissance exacte du Coran d'autant que, contrairement à une idée reçue, l'ésotérique (bātinin) n'exclut en aucune façon l'exotérique (z̧āhir ${ }^{47}$. Quoi qu'il en soit, retenons de la description amplifiée et mythifiée que font Ibn Nașr et Ibn Sibāṭ d'al-Sayyidlefaitqu'il futun savantversé dansl'ésotérisme druze toutenétant un fin connaisseur des principales sources de l'islam.

Sa réputation de savant et d'homme de religion lui valut la confiance de ses contemporains dont certains se soumirent délibérément à son arbitrage

45 Ibn Sibāṭ, Ta'rīh ho p. 879-884.

46 Sur la place du Coran dans la Hikma, voir De Smet, Épîtres sacrées, p. 71-72.

47 Pour un exposé plus complet, voir Mohammad Ali Amir-Moezzi, «Notes sur deux traditions "hétérédoxes" imāmites», Arabica, 41/1 (1994), p. 127-133; et De Smet, «Zâhir et bâtin », p. 1387-1388. Sur l'histoire de l'ésotérisme, voir Mohammad Ali Amir-Moezzi (dir.), L'ésotérisme shi 'ite: ses racines etses prolongements/Shi 'i Esoterism: it's Roots and Developments, Turnhout, Brepols («Bibliothèque de l'École des hautes études. Sciences religieuses », 177), 2016. 
(tahkìm) pour résoudre leurs litiges ${ }^{48}$. Ibn Sibāṭ brosse un tableau idyllique de la juridiction arbitrale d'al-Sayyid quand son contemporain, Ibn Nașr, l'évoque succinctement :

Les [plaideurs] qui s'opposaient acceptèrent [son jugement] sans affrontements ni emprisonnement ni violence. Il réprimandait chaque igno$\operatorname{rant}(\check{g} \bar{a} h i l)$ qui lui rendait visite, tranchait [les litiges] en prononçant sa sentence $(\mathrm{hukm})$, résolvaitchaque difficulté, rectifiaitchaque égarement et éliminait tous les périls ${ }^{49}$.

Il convient de préciser que l'arbitrage d'al-Sayyid s'inscrivait dans une pratique courante de lajustice qui lui préexistaitalors dans lemilieurural du Ġarb. Mais l'émirn'avaitaucun pouvoircoercitifet, parconséquent, lamiseen application desa sentencereposait, d'un côté, surl'engagementpréalabledesplaideursàse soumettre à son jugement et, de l'autre, sur la pression sociale qui pouvait être exercée contre la partie qui refusait le résultat de l'arbitrage. Al-Sayyid aurait également rempli la fonction de médiateur, quand bien même seul Ibn Nașr en fait vaguementmention: «Il réconcilia les sujets et leurordonna [d'agir avec] droiture $»^{50}$.

Toutefois, le mode de résolution des litiges à l'époque d'al-Sayyid se distingue nettement de la théorie judiciaire décrite dans les premiers traités de droit druze, dont les auteurs élaborent un système juridictionnel qui articule la médiation (șulh)des cheikhs religieux et lejugement du sāyis, uninitié dehaut rang remplissant la fonction non officielle de juge au sein de la communauté des adeptes ${ }^{51}$. En plus d'élaborer un système judiciaire fondé notamment sur le texte sacré de la Hikma, les juristes postérieurs à al-Sayyid font la part belle à la médiation et évoquent épisodiquement la sentence arbitrale. Le tahkim apparaît somme toute comme une pratique répandue du vivant d'al-Sayyid à laquelle avait recours tout individu indépendamment de son appartenance religieuse, tandis que la théorie juridique post-sayyidienne considère le sulh comme le mode privilégié de résolution des litiges entre adeptes druzes.

48 Pour un développement plus approfondi sur le système arbitral d'al-Sayyid, voir Wissam H. Halawi, «L'arbitrage et la médiation des cheikhs religieux druzes du Garb au IXe/XVe siècle», Revuedes Mondes MusulmansetdelaMéditerranée, 140(2016), p.103-108.

49 Halawi, «Kitāb Durrat al-tā̆g », p. 158.

50 Halawi, «Kitāb Durrat al-tā̆ $»$, p. 157. C'est nous qui soulignons.

51 Pour un exposé détaillé de la théorie judiciaire druze, voir Halawi, «L'arbitrage et la médiation», p. 108-117. Sur l'institution du sāyis, voir Halawi, Le druzisme au IXe/XVe siècle, p. $434-440$. 
Cette évolution de la pratique de la justice vers un système institutionnalisé et hiérarchisé participe de la théorisation d'un système normatif druze ; le rôle d'al-Sayyid y est toutefois ambigu. Bien que ses hagio-biographes le considèrent comme l'auteur du droit druze, les règles qu' ils lui attribuent sont en effet imprécises comme le montre un bref passage du discours de Mir 'ī où l'auteur énumère des thèmes (mariage, divorce, charité, aumône, justice $)^{52}$ qui furent minutieusement précisés plus tard dans les traités juridiques. De son côté, Ibn Sibāṭ accorde à l'émir une série de préceptes moraux et des restrictions communes aux communautés musulmanes en terre d'Islam, à l'instar de l'interdiction de consommer du vin (hamr) et toute boisson enivrante (manākir, muskirāt $)^{53}$.

Pourtant, al-Sayyidsembles'êtredistinguéparunedoctrinereligieusestricte. Ses disciples, notamment Ibn Nașr, indiquent qu'il auraitœuvré pourinstaurer une pratique religieuse (' $a m a l$ ) pure et pour expliquer le sens profond (bātin) de la Hikma, mais qu'il aurait aussiréservéla lecture de cetexte sacré aux seuls « initiés méritants » ${ }^{54}$. Or, si nous pouvons raisonnablement penser qu'il fut un maître spirituel de renom ayant entamé une certaine réforme juridico-religieuse, les sources dont nous disposons ne nous permettent pas de préciser davantage l'étendue ou la nature exacte de son action. Quoi qu'il en soit, l'autorité qu'il exerçait sur ses disciples reposait à la fois sur son magistère spirituel, son prestige social et ses qualités personnelles. Ainsi, tout porte à croire que, de son vivant, l'émir ne fonda aucune école juridique ou théologique; il n'élabora pas non plus un quelconque système normatif ou judiciaire. L'émir al-Sayyid prodiguaplutôt un enseignement savant personnel queses disciples perpétuèrent, développèrent et systématisèrent après sa mort. Le druzisme à son époque n'était en définitive qu'à un stade encore archaïque; en d'autres termes, il était enseigné par des maîtres spirituels, dont al-Sayyid est la figure la plus accomplie, mais il ne possédait ni théorie juridique ni institutions lui permettant de régler la vie quotidienne des adeptes.

52 Mir'̄ị, MS Berlin, Staatsbibliothek, Ldbg 210, fol. 254r-v; Halawi, Ledruzisme au IXe/XVe siècle, p. 317 (trad.), p. 573 (éd.).

53 Halawi, «La réforme druze», p. 114-115.

54 Pour le discours d'Ibn Nașr, voir Halawi, «Kitāb Durrat al-tāğ», p. 147-157; pour celui de Mir '⿳亠丷⿵冂丶, voir MS Berlin, Staatsbibliothek, Ldbg 210, fol. 250v et 254r, et Halawi, Le druzisme auIXe/XVe siècle, p. 301 (trad.),p. 571 et 573 (éd.). Précisons qu'en tant que maître spirituel, al-Sayyid, selon ses hagio-biographes, était le seul à pouvoir désigner les personnes qui méritaientd'avoiraccèsàlaHikma-d'oùl'expression «initiéméritant»(mustahiqqūn). 


\section{2- Formation du madhab ou école théologico-juridique druze}

Le droit druze connut durant la seconde moitié du $\mathrm{IX}^{\mathrm{e}} / \mathrm{XV}^{\mathrm{e}}$ siècle et la première moitié du siècle suivant une évolution dont les étapes demeurent difficiles à identifier avec précision. En effet, la littérature hagiographique et narrative attribue à l'émir al-Sayyid un enseignement spirituel et juridiquequi semble être rudimentaire, alors que les traités d'exégèse et de droit, rédigés après sa mort, décrivent une doctrine théologique et juridique systématique. Pourtant, si l'on en croit les sources inédites rédigées aux $\mathrm{XI}^{\mathrm{e}} / \mathrm{XVII}^{\mathrm{e}}$ et $\mathrm{XIII} /$ $\mathrm{XIX}^{\mathrm{e}}$ siècles, al-Sayyid apparaît comme le fondateur du fiqh druze $^{55}$. Les auteurs druzes actuels, on l'a vu, considèrentégalement qu'il est la seule autorité juridique au sein de la communauté. N'ayant à aucun moment remis en question ce discours idéologique, les études druzes ne se sont interrogées ni sur les origines ni sur l'évolution du droit druze, ni encore sur ses caractéristiques. Par conséquent, le druzisme continue d'être considéré comme une simple doctrine théologique, et le droit druze comme une adaptation locale du droit hanafite ottoman ${ }^{56}$.

55 VoirMS Munich, Staatsbibliothek, Ar. 230, fol.44v; MS Paris, BnF, Arabe 1437, fol. 131r; MS Paris, BnF, Arabe 4663, fol. 9r-13r.

56 Plusieurs études ont été menées sur le code du statut personnel adopté par les Druzes : voir James Norman Dalrymple Anderson, « The Personal Law of the Druze Community », Die Welt des Islam, N.S. 2/1 (1952), p. 1-9, 83-94 ; Aharon Layish, « Prohibition of Reinstating a Divorced Wife in the Druze Family », Bulletin of the School of Orientaland African Studies, 41/2 (1978), p. 258-271; id., Mariage, Divorce and Succession in the Druze Family: A Study based on decisions of the Druze arbitrators and religious courts in Israel and the Golan Heights, Leyde, Brill («Social, Economic and Political Studies of the Middle East», 31), 1982 ; Mursil Nașr, al-Ahwwāl al-šahșiyya li-l-țā ifa l-durziyya : naz̧ra fì l-šurūt wa-l-ahkām wa-l-iğtihādāt, Londres, Druze Heritage Foundation, 2009; id., Tatawwur qaḍa 'al-muwahhidīnal-durūz 'abral-tārīhwa-ușūlal-mahkamātal-šar 'iyyali-ğāyatsanat 2005, Londres, Druze Heritage Foundation, 2011 ; Sulaymān Taqīl-Din et Nāyil Abū Šaqrā

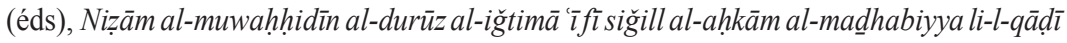
l-šayh̆SalmānAḥmadTaqūl-Dīn(1866-1870), Beyrouth, Dārišāāātli-1-țibā a wa-l-našrwa-ltawzī' , 2000 ; Ḥalīm Taqī al-Din, al-Aḥwāl al-šahșiyya 'inda l-durūz wa-awğuh al-tabāyun ma a l-sunna wa-l-šs̆ a : mașdaran wa-ğtihādan, Beyrouth, al-Mağlis al-durz̄i li-l-buhūt wa1-inmā', 1981 ; Lubna Tarabey, Family Law in Lebanon: Marriage and Divorce among the Druze, Londres-New York, I.B. Tauris, 2013. Anderson et Layish se trompent lorsqu' ils estiment que l'adoption du droit hanafite par les juristes druzes actuels relève du principe de la taqiyya (dissimulation) car, d'une part, le code druze contient des particularités notables qui diffèrent des prescriptions hanafites ; d'autre part, le système juridique que décrivent les traités inédits de droit d'époque médiévale est informel et concerne uniquement les initiés, alors que le Code s'adresse aux non-initiés. Dans l'introduction à son ouvrage Mariage, Divorce and Succession, Aharon Layish tente pourtant d'expliquer ces 
Afin d'éviter toute confusion terminologique, il convient de préciser que les spécialistes de l'époque contemporaine appellent à tort «droit druze » ce qui correspond en fait au « Code du statut personnel de la communauté druze» qui fut adopté au Liban, en Syrie et en Israël respectivement en 1948, 1953 et 1962 et qui donna naissance à une « juridiction religieuse druze» ( $a l-$ qad $\bar{a}^{3}$ al-madhabì $l$-durzì) reconnue par ces trois États ${ }^{57}$. Mais les initiés druzes n'accordent à cette juridiction qu'une importance secondaire, les véritables principes et règles de droit étant, à leurs yeux, ceux qui sont attribués à l'émir al-Sayyid et dont les fondements sont gardés jalousement par les religieux.

Dans cette partie, nous tenterons de répondre à deux questions majeures : comment les « cercles d'initiation » étaient-ils organisés du vivant d'al-Sayyid? Et comment le figh druze peut-il être conçu comme l'aboutissement d'une évolution d'une «école personnelle» attribuée à al-Sayyid vers une «école théologico-juridique druze», le sayyidisme? Mais précisons, au préalable, ce quenous entendons par «cercles d'initiation», «écolepersonnelle» et «école juridique ou madhab druze ».

Les travaux de Wael Hallaq distinguent la scholarly school[II] d'un juriste dont la doctrine n'était pas suivie de manière exclusive par ses étudiants et la personal school ou doctrine juridique d'un 'ālim que certains de ses étudiants transmettaient fidèlement, de la doctrinal school qui se caractérise par a cumulative doctrine of positivelawin which the legal opinions of the leading jurist, now the supposed founder of the school, were, at best, primi inter pares, and at least, equal to therest of theopinions and doctrines held byvarious other jurists, also considered leaders within the school ${ }^{58}$. Wael Hallaq montre également que l'émergence de ces typologies d'écoles eut lieu après une période où le fiqh était discuté par des savants musulmans (scholarly circles [I]) qui ne possédaient pas encore de méthodologie claire ou de raisonnement juridique à proprement parler permettant d'attribuer un enseignement à un maître de manière nominative $\mathrm{e}^{59}$. Bien que cette typologie des mad $\underline{d} \bar{a} h i b$ proposée par

particularités en faisant vaguement référence à des textes juridiques attribués à l'émir al-Sayyid qu'il n'a pas pu consulter.

57 Le Codeadoptéau Liban est aujourd'hui accessible en ligne: www.druzepersonalstatus. gov.lb; voir la traduction en anglais de Tarabey, Family Law, p. 214-226. Sur les Codes en Israël et en Syrie, voir Layish, Mariage, Divorce and Succession, p. 10 et Amīn Muhammad Țalī',Aṣlal-muwaḥhidīnal-durūzwa-ușūluhum, Beyrouth, Dāral-Andalus, 1961,p. 148. Sur lajuridiction religieuse druze au Liban, voir Edmond Rabbat, La formation historiquedu Liban politique et constitutionnel: essaide synthèse, Beyrouth, Publications de l'Université Libanaise, 1986,p. 133-137.

58 Wael Hallaq, The Origins and Evolution of Islamic Law, Cambridge, Cambridge University Press («Themes in Islamic Law», 1), 2005, p. 156.

Voir ibid., p.57-68. 


\section{Hallaq pour décrire la formation et l'évolution des écoles juridiques en Islam}

ne puisse pas être appliquée à l'histoire du fiqh druze, elle offre une base de réflexion théorique sur l'émergence du sayyidisme (voir fig. 2$)^{60}$.

60 La définition de madhab et le moment à partir duquel un enseignement juridique devient une école de droit en Islam ne font pas l'unanimité parmi les spécialistes du droit musulman. Citons en particulier les travaux complémentaires de George Makdisi, The Rise of the Colleges: Institutions of Learning in Islam and the West, Edimbourg, Edinburgh University Press, 1981 ; et de Christopher Melchert, The Formation of the Sunni Schools of Law,9th-10th Centuries C.E., Leyde-New York-Cologne, Brill(«Studies in Islamic Law and Society », 4), 1997. Ce dernier montre qu' un madhab prend le sens de school of law lorsqu'il possède à la fois un chef local, une production de commentaires de ses principales œuvres juridiques, notamment les muhtașars, et une transmission structurée du droit. À cela, Robert Gleave ajoute la fondation d'une doctrine juridique solide; il écarte par ailleurs l'hypothèse de Devin Stewart selon laquelle se conformer à la discipline des ușūlal-fiqh serait l'une des conditions de la formation d'un mad hab. Voir Robert Gleave,

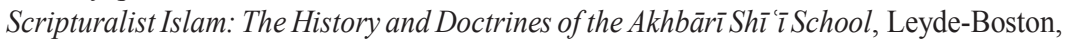
Brill («Islamic Philosophy, Theology and Science», 72), 2007,p. 140, n. 1; Devin J. Stewart, Islamic LegalOrthodoxy: Twelver ShiiteResponses totheSunniLegalSystem, Salt Lake City, University ofUtah Press, 1998, p. 175-208. De son côté, Wael Hallaq propose un modèle distinct pour décrire l'évolution et la formation d'un madhab (voir fig. 2). Nous empruntons ce modèle pour étudier la formation du madhab druze, car il s'adapte le mieux aux indications qu'en fournissent nos sources narratives et juridiques. Toutefois, il convient de préciser que, d'un point de vue méthodologique, les sources utilisées par Hallaq sont anachroniques par rapport aux événements que nous analysons, l'émergence de la première école de droit druze ayant eu lieu plusieurs siècles après la formation des premières écoles juridiques en Islam. Cela suppose que la notion de madh $a b$ n'était pas nouvelle pour les juristes druzes, lesquels auraient pu ainsi suivre le modèle des autresécoles existantes pour élaborer leur doctrine juridique. Mais en s'appuyant sur les traités de droit druze (les Šarhayn), nous constatons que ces juristes n'essaient pas d'imiter les spécialistes en la matière ou les écrits attribués aux fondateurs éponymes des autres écoles juridiques ou encore de démontrer l' " orthodoxie » de leur doctrine. Selon eux, il va de soi que le madhab druze est supérieur à tout autre madhab en Islam; par conséquent, leur théorie juridique serait la seule à satisfaire la volonté de Dieu et à assurer le salut des adeptes. Deplus, les Šarḥaynne sont pas organisés à la manière de la plupart des ouvrages de fiqh: l'ordre des chapitres ne respecte aucune logique juridique claire et les thèmes abordés semblent être choisis en fonction de leur pertinence au sein de la société locale. Rappelons également que les juristes druzes écrivent dans un contexte rural n'ayant pas connu de production savante de taille. Notre connaissance de la littérature juridique et théologique druze, produite entre le IXe/XVe siècle et nos jours, nous permet enfin d'affirmer que les religieux druzes n'ont jamais rédigé un précis de droit (muhtașar) ou de commentaires de leursécrits juridiques; etmêmes'ils distinguent les étudiants débutants des grands initiés, ils n'ont jamais produit non plus un certificat équivalent à l'iğāza. Dans le sanctuaire connu sous le nom d'al-Bayāḍa, situé au sud du mont Liban actuel et étant, aujourd'hui, le plus grand centre d'enseignement druze de la région Syrie-Liban-Isräl, la transmission du savoir théologique et juridique, ainsi que l'initiation à la doctrine druze, se feraient à notre connaissance oralement entre maîtres-initiés et étudiants. 


\begin{tabular}{|c|c|c|}
\hline & $\begin{array}{l}\text { Typologie des mad̄āhib proposée par } \\
\text { Wael Hallaq }\end{array}$ & Hypothèse de typologie des écoles druzes \\
\hline 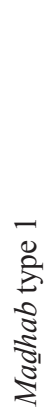 & $\begin{array}{l}\text { Cercles de savants I } \\
\text { ou scholarlycircles } \\
\text { Le savant n'a ni une méthodologie claire ni un } \\
\text { raisonnement juridique systématique. } \\
\text { Les thèmes débattus ne figurent pas forcé- } \\
\text { ment dans la théorie juridique ultérieure. }\end{array}$ & $\begin{array}{l}\text { Cercles d'initiation } \\
\text { de maîtres spirituels ignorés par les sources } \\
\text { Enseignement du Coran et initiation à la Hikma } \\
\text { Opinion personnelle sur des préceptes moraux } \\
\text { Opinion juridique? } \\
\text { Les sources n'indiquent aucun maître, à l'excep- } \\
\text { tiondel'émirSayfal-Dīn Yahyā(m. 864/1459- } \\
\text { 1460) qui aurait été le maître d'al-Sayyid. }\end{array}$ \\
\hline 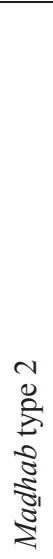 & $\begin{array}{l}\text { Cercles de savants II } \\
\text { ouscholarlycircles } \\
\text { Le maître élabore sa propre méthodologie et } \\
\text { une conception individuelle du droit. } \\
\text { Un étudiant assiste à plusieurs cercles d'en- } \\
\text { seignement, puis devient maître lui-même et } \\
\text { transmet à ses étudiants la doctrine de son } \\
\text { maître en l'adaptant à sa propre vision. }\end{array}$ & $\begin{array}{l}\text { Cercles d'initiation (mağālis) } \\
\text { d'al-Sayyid et de ses disciples } \\
\text { L'émir al-Sayyid (m. 884/1479) réunit ses élèves } \\
\text { une fois par semaine pour leur } \\
\text { transmettre son enseignement. } \\
\text { Ses disciples tels qu'Ibn Nașr (m. 898/1492) et } \\
\text { Abū 'AlīMir '̄i(m. 900/1495) transmettent à leurs } \\
\text { élèves sa doctrine dans leurs villages d'origine. } \\
\text { Doctrine d'al-Sayyid : enseignement } \\
\text { spirituel(Coran, Hikma) et visionjuridique } \\
\text { rudimentaire. }\end{array}$ \\
\hline 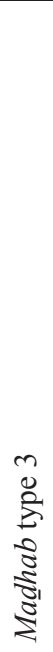 & $\begin{array}{l}\text { Écoles personnelles } \\
\text { ou personal schools } \\
\text { Le maître possède un maḍhab et } \\
\text { transmet sa doctrine à ses étudiants. } \\
\text { Un étudiant n'est pas forcément fidèle } \\
\text { à la doctrine de son maître et peut, soit } \\
\text { changerd'école, soitenadopterplusieurs } \\
\text { simultanément. } \\
\text { Condition sine qua non pour que le mad̆hab } \\
\text { d'unjuriste soit considérée comme une «école } \\
\text { personnelle : un groupe d'étudiants ( } a s ̦ h a \bar{a} b) \\
\text { doit adopter exclusivement la doctrine de leur } \\
\text { maître. }\end{array}$ & $\begin{array}{l}\text { École personnelle } \\
\text { d'al-Sayyid } \\
\text { Les sources hagiographiques attribuent au seul } \\
\text { émir al-Sayyid (m. 884/1479) une doctrine } \\
\text { juridique personnelle dont les principes et la } \\
\text { méthodologie sont toutefois ambigus. } \\
\text { Les «Sayyidiens», disciples d'al-Sayyid, sont } \\
\text { fidèles à la doctrine du maître et l'adoptent } \\
\text { exclusivement. } \\
\text { D’autres écolespersonnelles, concurrentesà } \\
\text { celle d'al-Sayyid, auraient existé vers la fin du } \\
\text { IXe/XVe siècle. }\end{array}$ \\
\hline
\end{tabular}




\begin{tabular}{|c|c|c|}
\hline & $\begin{array}{l}\text { Typologie des madāhib proposée par } \\
\text { Wael Hallaq }\end{array}$ & Hypothèse de typologie des écoles druzes \\
\hline 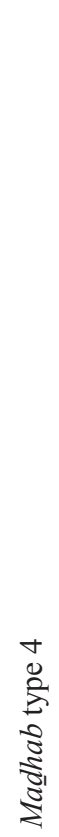 & $\begin{array}{l}\text { Écoles juridiques } \\
\text { ou doctrinal schools } \\
\text { La doctrine juridique de l'école est un cumul } \\
\text { de plusieurs théories juridiques. } \\
\text { Aucune contradiction n'existe entre la doc- } \\
\text { trine du fondateur éponyme et celle exprimée } \\
\text { par les juristes éminents de l'école. } \\
\text { Chaque école se distingue par sa méthodo- } \\
\text { logie juridique, ses principes de droit et son } \\
\text { corpus de droitpositif. } \\
\text { Chaquejuriste adopte et applique fidèlement } \\
\text { le système juridique de son école. }\end{array}$ & 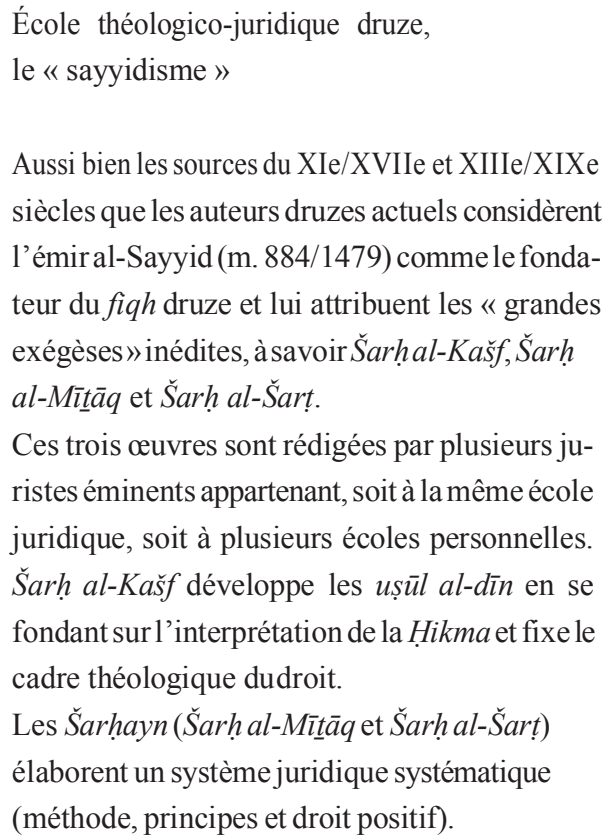 \\
\hline
\end{tabular}

figure 2 Typologie des écoles juridiques druzes.

Note: Voir Hallaq, The Origins and Evolution of Islamic Law, chap. 7.

Ainsi, nous appelons «école personnelle»l'enseignement théologique et juridique d'un maître spirituel druze, icial-Sayyid, lequel développa sa doctrine en s'appuyant sur son interprétation ( $t a$ ' wìl) de la Hikma. D'après les sources hagiographiques, la doctrine d'al-Sayyid semble avoir été adoptée et transmise fidèlement par ses disciples, les «Sayyidiens » ${ }^{61}$. Toutefois, à la différence de la personal school en Islam, al-Sayyid, on l'a vu, ne semble avoir élaboré aucunethéorie juridique systématique. Ses contemporainsévoquent parailleurs les assemblées (mağālis) d'initiés qu'il tenait hebdomadairement à 'Abayy et

$61 \quad$ Nous appelons « Sayyidiens » le parti d'al-Sayyid que formaient ses vingt-sept élèves lesquels transmettaient son enseignement dans leurs villages d'origine; pour un exposé plus complet, voir Halawi, Le druzisme au IXe/XVe siècle, p. 338-347. Contrairement aux propos tenus par les auteurs druzes actuels qui considèrent le sayyidisme comme une doctrineadoptéeparl'ensemble desadeptes en Syrie,leréseau d'influence développépar les Sayyidiens ne dépassait pas la région rurale du Ġarb et du Šūf. 
celles que ses disciples présidaient dans leurs villages d'origine du Ġarb et du Šüf pour transmettre la doctrine du maître ${ }^{62}$. Cela montre clairement que l'enseignement religieux se déroulait alors dans des « cercles d'initiation» et que les Sayyidiens étaient tantôt des élèves tantôt des maîtres spirituels. À cette période, d'autres cercles d'initiation auraient pu être tenus par des cheikhs locaux anonymes qui avaient également leur propre opinionjuridique et leurinterprétation des textes sacrés. Quoi qu'il en soit, tout porteà croire quejusqu'à la fin du IX $/ \mathrm{XV}^{\mathrm{e}}$ siècle l'opinion ou la doctrine juridique d'un savant druze consistait à définir le licite et l'illicite en matière d'éthique et de morale, et ce en s'appuyant à la fois sur la Hikma et le Coran ${ }^{63}$.

Quant au «madhab druze» que nous désignons par « sayyidisme», il correspond à la doctrinal school décrite par Hallaq. En effet, le système juridique élaboré dans les deux traités de droit Șarh al-Mītâqq et Šarh al-Šarț-quenous appelons les Šarh̆ayn-, ainsi que les ușül al-dīn (principes de la religion) explicités dans le Šarḥ al-Kašf sont attribués au seul émir al-Sayyid, fondateur éponyme du fiqh druze. Ces trois «grandes exégèses » inédites décrivent une doctrinethéologico-juridiquequenulsavantnepeut contredirevoireinnoverles religieux étant tenus de l'expliquer ( $̌$ ar $h$ h $)$ et de l'appliquer fidèlement ( $t a-$ $q l \bar{\imath} d$ )-, alorsqu'un examen minutieux de leurcontenumontre qu'ils'agit derecueils de plusieurs textes rédigés par des autorités religieuses différentes ${ }^{64}$. En faisant la distinction entre «mad l'hypothèse prudente que plusieurs écoles personnelles druzes contemporaines de celle d'al-Sayyid ont pu exister et, de surcroit, que d'autres conceptions individuelles du droit ont pu également être développées sous l'autorité de savants, disciples ou pas d'al-Sayyid, sans pour autant donner naissance à une école personnelle. Rappelons que les sources hagiographiques indiquent qu'al-Sayyid fut accusé d'innovation religieuse par ses opposants. Les divergences doctrinales entre ces différents mad āhib auraient été gommées lors du processus de canonisation des " grandes exégèses », probablement à l'initiative des Sayyidiens et de leurs étudiants. Ces œuvres décrivent ainsi des principes juridiques homogènes, quand bien même la casuistique révèle certains écarts au sein du corpus du droit positif.

62 Pour la description des mağālis d'al-Sayyid, voir Halawi, «La réforme druze », p. 117-118. Pour l'institution du mağlis druze, voir Halawi, Le druzisme au IXe/XVe siècle, p. 400-405.

63 Les sources du droit druze feront l'objet d'un prochain article. Pour une première approche, voir Halawi, Le druzisme au IXe/XVe siècle, p. 427-430.

64 Les caractéristiques matérielles de certains manuscrits nous autorisent à situer la productiond'unepartie decettelittératureverslafinduIXe/XVe siècle oudurantlapremière moitié du Xe/XVIe siècle; voirHalawi, Ledruzisme auIXe/XVe siècle, p. 535-561, en particulier les manuscrits B5, M2, P2 et P5. 
Dansles Šarhayn, le traitementduconsentement dela femmeaumariage est éclairant pour notre propos. Pour légiférer sur ce point, les juristes se fondent sur le principe religieux d'al-rida ā wa-l-taslìm (l'assentiment et la soumission), nous y reviendrons. Observons d'abord comment, à partird'un enseignement commun, les auteurs des Šarḥayn développent deux versions différentes des préceptes druzes qui doivent être respectés lors du mariage ${ }^{65}$ :

Dans les affaires de mariage, l'homme doit [se soumettre] aux préceptes absolus (farāi ị 'azìma) dont le fait de ne se marier qu'avec une femme unitaire (muwahhida); c'est le précepte le plus important, car se marier avec une non-unitaire est [un acte] extrêmement illicite (harām 'azīm) qui suscite la colère du Dieu des mondes. Puis, il faut qu'elle soit consentante (rādiya) et qu'elle [accepte sa proposition] de son propre gré et sans contrainte ( $\check{g} a b r)$. Elle doit ensuite se soumettre à lui (tusallim nafsahā ilayhi) et lui, de son côté, doit la traiter comme son égal (yusāwīhā bi-nafsihi) et partager équitablement avec elle ses biens (yunșifuhāmin ğamī'māffìyadihi). De plus, il ne doit se marier ni avec une déséquilibrée (mağnūna) ni avec une mutilée (muğad $\underline{d} d a m a)$, ni encore avec une invalide (ratq $\bar{a}^{\prime}$ ) ou une infirme (qazna $\bar{a}^{\prime}$ ). Et il ne doit pas se marier avec une femme sans son consentement ( $\dot{\text { gayr qubliha }}$ ), car [un tel acte] est le plus illicite de tous (ašadd al-ğamī tahrīman ${ }^{66}$.
Dans le mariage, l'homme juste et sincère est soumis (furida 'alayhi) à cinq préceptes ( $f a r a \bar{a}$ 'i $d)$, dont deux ont lieu avant l'union (ittișāl) - à savoir ne se marier qu'avec une femme unitaire (muwahhida) [...] et s'assurer qu'elle est consentante $[\ldots]$ - et trois autres après l'union (ittișāal) qui consistent à ce qu'une fois qu'elle se soumet à lui sans contrainte ( $\check{g} a b r)$ ou violence (qahr), il la traite comme son égal (yusāwin̄hā bi-nafsihi) dans la vie comme dans la religion et partage équitablement avec elle tout ce qu'il possède dans la vie (yunșifuhā min ğamī $m \bar{a} f \grave{\imath}$ yadihiminal-dunyā). Lorsqu'un homme se marie sans respecter l'un des cinq [préceptes] ci-mentionnés, il s'oppose aux règles de la vérité et au droit druze (šar 'al-tawhīd). Le premier des cinq [préceptes] consiste à [se marier avec] une femme unitaire (muwahhida), car se marier avec une non-unitaire est [un acte] illicite strictement prohibé (harām šadīd al-tahrīm). Le deuxième consiste à [ne pas] se marier avec une femme malgré

65 Notons que les savants druzes utilisent les vocables tawhīd, muwaḥhidūn, muwaḥhid et muwahhida pour désigner l'Unitarisme druze, que nous rendons par druzisme, les Unitaires druzes, ainsi que les hommes et femmes druzes. 
elle (qahran) ou sans son consentement ('gayr rädiva), car [l'inverse] est extrêmement illicite (harām 'azīm). Le troisième est, comme le deuxième, extrêmement illicite (harām 'azīm). Le quatrième et le cinquième-à savoirl'égalité etl'équité[sont obligatoires] car l'homme qui se marie avec sa femme en se soustrayant à l'égalité etàl'équité[commet]également [un acte] illicite $(\text { harām })^{67}$.

Bien que ces deux extraits présentent des différences non fondamentales et auraient ainsi été rédigés par deux juristes issus d'une même école personnelle, d'autres passages dans les Šarhayn se distinguent par une nouvelle vision du droit:

[Au moment de la $d a$ ' $w a$ ], les gens allaient bientôt abandonner l'obscurité des lois ( $\breve{s} a r a \bar{\imath} i)$ [positives] où le mariage se passe à l'inverse de [ce qu'autorise] la doctrine druze (madhab al-tawhīd), car, dans les lois positives (al-šarā' 'i al-nāmūsiyya), la femme est forcée ( $q a h r$ ) et contrainte $(\dot{g} a s ̧ b)$ et, de là, elle ne peut pas décider de son propre mariage. Toute personne qui s'oppose à cela désobéit à Dieu, d'après le texte (nașș) de la loi positive (al-šarì a l-nāmūsiyya). Celle-ci est contraire au droit druze (šarī'atal-tawhīd) lequel respecte [le principe] de «l'acceptation et dela soumission » (al-riḍa wa-l-taslīm) dans le cas du mariage entre Unitaires (muwahhịidūn). L'Imam de la Vérité (imāmal-haqq) ${ }^{68}$ fit alors cette disposition (šart $)$ aux Unitaires comme une bougie qu'il allumait pour leur annoncer leursortie éminente de l'obscurité des šarā 'i $i$. [...]Al-riḍa $w a-$ l-taslìm signifie ici que la femme est consentante (rādilya) et résignée (musallima)àépouserl'hommesansviolence (qahr)nicontrainte ( $\dot{g} a s ̣ b)$ mais plutôt de sa propre volonté. [...] Le mariage de la femme malgré elle (qahran) est strictement interdit (harām maḥd) et correspond à un acte d'adultère $(z i n \bar{a}) ; 1$ 'homme qui le fait est une personne adultère $(z \bar{a} n \bar{l})$ et ses enfants sont des enfants adultérins (awläd zināa). Car cela

67 Šarha al-Mītāâq, MS Berlin, Staatsbibliothek, Ldbg 211, fol. 54r-v.

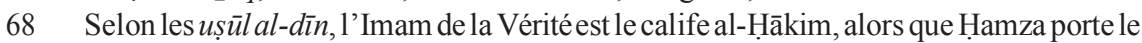
titre de l'Imam du Temps (imāmal-zamān) ou de l'Imam suprême (al-imām al-a 'zam), ou encore celui du Résurrecteur de la Vérité ( $q$ à im al-haqq) et/ou de cette époque (alzamān); Šarh al-Kašf, MS Munich, Staatsbibliothek, Ar. 229, fol. 48v, 65v. Pour l'utilisation de ce dernier titre dans la Hikma, voir De Smet, Épitres sacrées, p. 65. 
serait un manquement au droit druze ( $\check{s} a r^{\prime}$ 'al-tawhìd), le mariage entre Unitaires étant [synonyme] d' " assentiment et [de] soumission» (rid̄a wa-taslimm ${ }^{69}$.

En somme, certains savants considèrent qu'un mariage conclu contre le gré de lafemme eststrictementillicite( harām), alorsqued'autres l'assimilentenplus à un acte d'adultère $(z i n \bar{a})$. La violation du principe d'al-riḍa wa-l-taslìm et, par conséquent, des règles de droit positif qui en découlent ne conduit ainsi pas aux mêmes conséquences juridiques chez les juristes druzes.

L'une des raisons ayant incité ces derniers à accorder à al-riḍ̂a wa-l-taslìm une importance capitale est le fait que ce principe, qui apparaît clairement ici comme un principe de droit, est également un principe théologique fondamental dans le druzisme. Il est en effet considéré dans le Šarh al-Kašf comme l'un des dix piliers de la religion druze qu'énumère le traité no 8 de la $\mathrm{Hikma}^{70}$. Et, en plus d'être le titre du traité no $16^{71}$, al-riḍ̂ wa-l-taslìm apparaît dans le traité no 25 comme une prescription à laquelle doivent se conformer les cheikhs pour régler les affaires de mariage entre hommes et femmes unitaires ${ }^{72}$.

Quantà l'adultère, il estégalementun concept de théologie queles exégètes druzes étayent dans le Šarh al-Kašf $f^{3}$. Ainsi ces derniers distinguent, d'un côté,

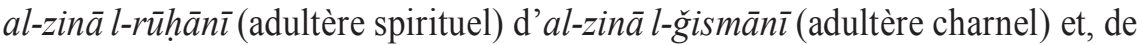
l'autre, al-zinā l-bātin (adultère intérieur) d'al-zinā l-ẓāhir (adultère visible). Parconséquent, les deux doublets spirituel/charnel et intérieur/visible du zinā

69 Šarhal-Šart, MS Munich, Staatsbibliothek, Ar. 232, fol. 16r-17v.

70 Dans le traité no 8, l'imam s'adresse aux femmes unitaires pour leur indiquer qu'en plus des trois préceptes capitales (connaissance de «Notre Seigneur», du Résurrecteur et des dignitaires), elles doivent observer les sept vertus qui abrogent et remplacent les sept piliers de l'islam; il précise ensuite que ces vertus doivent également être observées par leshommes unitaires; voir DeSmet, Épitressacrées, p. 191(trad.), p.508(éd.). Or, dansle Šarh $a l-K a s ̌ f, l$ 'exégète fait référence à ce traité pour indiquer dix préceptes capitaux dont le neuvième est al-rị̂ā wa-l-taslīm, le dixième précepte d'al-muharramāt wa-l-muhallalāt qu'il adopte ne figurant pas dans le traité en question; voir Šarh al-Kašf, MS Munich, Staatsbibliothek, Ar. 229, fol. 109v-111r.

71 Pour ce traité, voir De Smet, Épittres sacrées, p. 318-328 (trad.), p. 614-622 (éd.). Les exégètes druzes associent l'assentiment à l'acceptation absolue du « Résurrecteur de cette époque » ( qä 'im al-zamān) et la soumission à l'attitude que les unitaires doivent avoir vis-à-vis de «la forme que revêtl'humanité(nāsūt) de Dieu»(al-șüraal-nāsūtiyya); Šarh al-Kašf, MS Munich, Staatsbibliothek, Ar. 229, fol. 111r.

72 Voir De Smet, Épîtres sacrées, p. 373-374 (trad.), p. 657 (éd.).

73 Šarh al-Kašf, MS Berlin, Staatsbibliothek, Ar. 228, fol. 22r-26r. Dans la théologie druze, la notion d'adultère est le résultat de la création ex nihilo de l'Adversaire contre la volonté spirituelle de l'Intellect, ce qui renvoie à l'opposition que connurent les prédicateurs druzes au cours de la da'wa. 
donnent naissance aux awlād al-zinā (enfants adultérins) lesquels sont accusés, soit de renoncer en leur for intérieur aux préceptes du tawhīd druze, soit d'adopter les lois positives ( $a l$-šarā' $i$ 'al-nāmūsiyya) qui les autorisent voire les poussent à commettre l'adultère ${ }^{74}$. Les lois positives sont, dans ce cas, associées au zinā l-bătin et les actions des hommes, à l'instar d'al-zina a bi-l-nisă ' (adultère commis contre les femmes), au zina $l$ l-zāahir. Autrement dit, l'adultère que les gens commettent ostensiblement à travers leurs actes est la conséquence de l'adultère qu'ils commettent subrepticement dans leur cœur en refusant de se soumettre à la volonté du Créateur.

Les savants druzes élaborent ainsi, dans le Šarh al-Kašf, les uṣūl al-dìn ${ }^{75}$ propres au druzisme et fixent le cadre théologique des principes et branches dufiqh druze; dans les ̌̌arhayn, lesquelsconstituent de véritables traités systématiques, ils détaillent sous une forme casuistique assez commune les normes qui régissent tous les aspects de la vie de l'initié conformément aux principes de la religion ${ }^{76}$. Voilà pourquoi, en se fondant sur les « grandes exégèses », nous pouvons considérer que le madhab druze est une école théologico-juridique

74 Contrairement aux awlād al-zinā, les awlädal-ḩaläl(enfants du bien), qui ne sont autres que les muwaḥhidūn (unitaires druzes), respectent et observent les marāsīm (édits) de leurs « véritables parents » (al-wālidān/al-ābāa' al-haqīqiyya) spirituels, l'Intellect universel et son épouse-auxiliaire l'Âme universelle; sur la théorie ismaélienne de l'Âme comme «épouse» de l'Intellect, voir Daniel De Smet, «La valorisation du féminin dans l'ismaélisme țayyibite: le cas de la reine yéménite al-Sayyida Arwā(1048-1138)», Mélanges de l'Université Saint-Joseph, 58 (2005), p. 110 et suivantes. La théologie druze associe ainsi la soumission et l'acceptation ( al-riḍāwa-l-taslīm) aux actions et préceptes d'al-Ḥākim (forme humaine de Dieu, le nāsūt) et del'Intellect Hamza ( $q \bar{a}$ 'im al-zamān); elle associe par ailleurs le respect et l'observance ( $a l-t \bar{a}^{\prime} a$ wa-l-itba $)$ aux règles spirituelles posées par le couple Intellect-Âme, c'est-à-dire Hamza et al-Tamīmī. En effet, les exégètes druzes du $\mathrm{IXe} / \mathrm{XVe}$ siècle distinguentles préceptes religieux énoncés dans la Hikma del'initiation spirituelle instaurée par l'Intellect (Hamza) et l'Âme (al-Tamīmī) au moment de la prédication; selon eux, les «bons unitaires» (al-muwaḥhidūnal-șāliḥūn) et les «enfants du bien » (awläd al-halāl) adhérèrent et se soumirent aux préceptes de la Hikma, respectèrent et accomplirent les enseignements des premiers prédicateurs druzes (Hamza et al-Tamīmī), tandis que les awlād al-zinā les rejetèrent catégoriquement.

75 Par uṣūlal-dīn ou principes de la religion, nous désignons la «théologie traditionnaliste» développée par les exégèses druzes en s'appuyant notamment sur la Hikma. Autrement dit, loin de se considérer eux-mêmes comme des mutakallimūn, les exégètes druzes utilisent une approche rationalisante pour expliquer des concepts religieux, dont $u s ̣ \bar{u} l$ al-ìmān ou principes de la foi. De plus, la théologie druze a une fonction défensive, permettant aux exégètes de défendre de manière rationnelle leurs traditions religieuses et juridiques contre les négateurs et les visions des autres doctrines.

76 Sur les grands thèmes du droit druze qui sont développés dans les Šarhayn, voir Halawi, Le druzisme au IXe/XVe siècle, p. 411-421, 430-434. 
où l'articulation entre théologie et droit rappelle le système hanbalite tel qu'il est décrit par George Makdisi ${ }^{77}$.

La formation de cette école vers la fin du $\mathrm{IX}^{\mathrm{e}} / \mathrm{XV}^{\mathrm{e}}$ siècle s' accompagne de l'émergence des premières institutions druzes, spirituelles et judiciaires. Ceci en dit long sur la volonté des autorités religieuses d'organiser alors la communauté des initiés selon des normes juridiques d'inspiration divine ${ }^{78}$. Toutefois, les sources n'indiquent pas les véritables raisons de cettevolonté réformatrice, l'hagiographie sayyidienne décrivant, on l'a vu, l'accroissement de l'ignorance chez les hommes et la dégradation morale et spirituelle de la société. À cette époque, le nombre des initiés aurait-il varié (à la hausse ou à la baisse) au point de nécessiter une organisation nouvelle? Des facteurs économiques (pauvreté, augmentation des taxes) ou naturels (épidémies) ${ }^{79}$ auraient-ils ravivé chez les savants druzes une vision eschatologique et apocalyptique déjà présente dans la Hikma les incitant à conduire leurs coreligionnaires vers le salut ? Toujours est-il que le contexte socio-politique de l'émergence du sayyidisme dans le Ġarb a sans doute été un facteur déterminant, quoique non exclusif, dans l'élaboration du système juridique druze et des institutions religieuses.

\section{3- Émergence des premières institutions druzes}

Les auteurs des Šarḥayn décrivent l'institution du sāyis avec une grande précision et la placent au centre de la juridiction druze ${ }^{80}$. Le sāyis, maître spirituel ayant acquis un haut degré d'initiation, remplit la fonction non officielle de juge au sein des communautés druzes; il statue ainsi sur les conflits des adeptes et s'entoure pour ce faire de témoins $(\check{s} u h \bar{u} d)$ privilégiés et de cheikhs religieux ou « hommes dignes de foi » (tiqqāt) qui forment un collège de médiateurs. Comme nous le montrons dans un précédent article concernant la procédure de divorce ${ }^{81}$, la médiation (șulh) est privilégiée dans le système

77 Voir George Makdisi, «L'islam hanbalisant», Revuedes Études Islamiques, H.S. 10 (1983), p. 63-68. Sur l'articulation entre kalām et fiqh chez les savants musulmans, notamment aux IIIe/IXe et IVe/Xe siècles, voir Melchert, The Formation of the Sunni Schools of Law, p. 68-86(chapitre4); A.Kevin Reinhart, BeforeRevelation: TheBoundaries of MuslimLegal Thought, Albany, State University of New York Press ( SUNY Series in Middle Eastern Studies »), 1995, p. 11-26.

78 À titre d'exemple, le șulh apparaît dans la théorie juridique druze comme un impératif divinévoquédans le traité no 66 de la Hikma; voir Halawi, «L'arbitrage etlamédiation», p. $110-112$.

79 Sur ce sujet, voir Halawi, «La réforme druze», p. 122-123.

80 Sur l'institution du sāyis, voir Halawi, Le druzisme au IXe/XVe siècle, p. 434-447.

81 Halawi, «L'arbitrage et la médiation », p. 108-117. 
judiciaire druze, si bien qu'elle doit être tentée avant la saisine du sāyis par l'une des deux parties et qu'elle peut intervenir à tout moment durant la procédure judiciaire, même après la prononciation du jugement. Fidèle aux principes de la religion, la théorie juridique considère que la conciliation est le meilleur moyen de prévenir un conflit ou de lui trouver une solution apaisée, afin de maintenir la cohésion du groupe conformément au précepte absolu de hifz al-ihwwān (protection des frères) établi dans la $\operatorname{Hikma}\left(\mathrm{n}^{0} 7,8,9,10,12\right.$ et 16) ${ }^{82}$ et largement commenté par les exégètes dans le Šarh al-Kašs $f^{83}$.

Le sāyis ne remplit toutefois aucune fonction officielle et, par conséquent, ne possède pas de pouvoir coercitif au sein de la société lui permettant de contraindre un initié à exécuter sa sentence. Ainsi, à défaut d'être en mesure de faire appliquer son jugement, il use de la force de l'acte d'excommunication (hağr) ou de celuid'exclusion $\left(i b^{`} \bar{a} d\right)$, ceproportionnellementà la gravité du délit. L'institution du sāyis apparaît par ailleurs comme une évolution par rapport à la justice arbitrale d'al-Sayyid qui était, on l'a vu, essentiellement fondée sur son autorité personnelle et qui s'adressait à la fois aux initiés druzes et aux personnesétrangèresà la communautédes religieux. D'autres institutions furent également établies après la mort d'al-Sayyid; alors qu'elles plongeraient leurs racines dans les usages locaux de la période sayyidienne, voire des périodes antérieures, elles furent institutionnalisées ultérieurement et reçurent dans les "grandes exégèses » une légitimation juridique et théologique.

Intéressons-nous d'abordàl'institution du waqfet dulegs (wașiyya). Letestament del'émir al-Sayyid inclut les biens meubles et immeubles qu'il constitua en waqf en faveur de ses proches, dont son épouse et ses disciples, et les biens qu'il donna en aumône aux membres de la communauté des initiés. Cela montre que, sinon la rédaction d'un testament, du moins le legs était alors une pratique courante ; les savants druzes en firent ensuite une doctrine théologique mais aussi juridique soumise à une certaine forme de rationalité spirituelle. La démonstration donnée par les exégèses dans le Šarḥal-Kašf mériterait un examen approfondi qui dépasse l'objet du présent article. Retenons toutefois que ces dernières se livrent à un raisonnement théologique extrêmement complexe afin de montrer que les auteurs des šarâ' $i$ ' al-nāmūsiyya ignoreraient le sens véritable de la norme coranique(Cor 4, 7 et 33) et, de là, se tromperaient sur la répartition des héritages et sur le droit du testateur de disposer d'un tiers de ses biens. Dansleursillage, les juristes jettent les fondements du droit druze

$82 \quad$ Voir De Smet, Épitres sacrées, p. 71, n. 305.

83 Šarhal-Kašf, MS Munich, Staatsbibliothek, Ar. 229, fol. 101v-106v. 
des successions ${ }^{84}$ où tout unitaire se trouve dans l'obligation de contourner le droit musulman successoral en léguant l'ensemble de ses richesses sous forme de donations charitables ou de waqfs constitués au profit des personnes de son choix. Pour en décider ainsi, les savants druzes invoquent le principe religieux d'awlād al-zinā auxquels ils incluent les parents biologiques du testateur qui doivent être écartés de la succession s'ils s'avèrent être de mauvais unitaires ${ }^{85}$.

Par ailleurs, la littérature narrative et hagiographique nous permet d'examiner l'évolution de l'institution du mağlis et l'émergence des institutions du chef de l'ésotérique et du chef religieux druze vers la fin du $\mathrm{IX}^{\mathrm{e}} / \mathrm{XV}^{\mathrm{e}}$ siècle. Alors que le mağlis fut un lieu d'enseignement, de sociabilité et d'influence à l'époque sayyidienne et continua de l'être ultérieurement, l'autorité religieuse d'al-Sayyidcédala placeà un pouvoir religieux bicéphaleausein delacommunauté (voir fig. 3). Ce nouveau pouvoir est inhérent au mağlis, celui-ci étant le lieu où l'enseignement spirituel est effectué et où la justice druze est exercée. Dans les sources druzes, le terme mağlis est polysémique car il désigne à la fois le «lieu de rassemblement» des initiés etl' «assemblée » des adeptes qui se déroule autour du grand-Initié d'un village ${ }^{86}$. Durant la seconde moitié du $\mathrm{IX}^{\mathrm{e}} / \mathrm{XV}^{\mathrm{e}}$ siècle, 'Abayy, village d'origine d'al-Sayyid, devint un véritable centre d'enseignement, du moins le seul que les sources évoquent. D'autres cercles d'initiation auraient existé à cette époque, mais il y a lieu de croire qu'ils sont demeurés ignorés par les auteurs médiévaux en raison sans doute de leur dimension modeste ou de la notoriété limitée de leurs maîtres spirituels.

En recevant en donation le lieu d'habitation et la bibliothèque privée de son maître al-Sayyid, Ğibrā' $11^{87}$ assura la continuité de l'institution du mağlis et la gouvernance spirituelle du groupe des Sayyidiens, voire de l'ensemble des initiés de la région du Ġarb et du Šŭf ${ }^{88}$. Ses contemporains indiquent dans

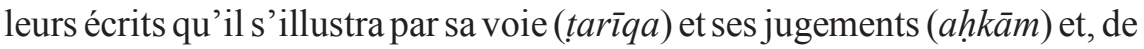
surcroît, qu'il dirigea les affaires des adeptes en suivant la doctrine de son maître ${ }^{89}$. Mais Ǧibrā' 1 ln' appartenait pas à l'élite rurale du Ġarb et ne connut

$84 \quad$ Le droit druze des successions ne se limite pas au legs ou au waqfet son examen nécessite une étude poussée que nous nous proposons d'effectuer dans un prochain travail.

85 Voir,entre autres, Šarh al-Mītāa $q$, MS Berlin, Staatsbibliothek, Ldbg 211, fol. 113v-114r.

86 Ibn Sibāț, Ta rīh , p. 881-883. Pour la description qu'en fait Ibn Nașr, voir Halawi, «Kitāb Durrat al-tāğ », p. 142, 155 et 157.

87 Sur ce personnage, fils spirituel d'al-Sayyid et un de ses plus grands disciples, voir Halawi, Le druzisme au IXe/XVe siècle, p. 362-367.

88 Sur les biens constitués waqfau profit de Ǧibrā'îl dans le legs d'al-Sayyid, voir Wașiyyat al-amīral-sayyid, MS Kaslik, Université Saint-Esprit, OLM 139, fol.23v et28r-v. Ibn Sibāt, Ta'rīh p. 896. 


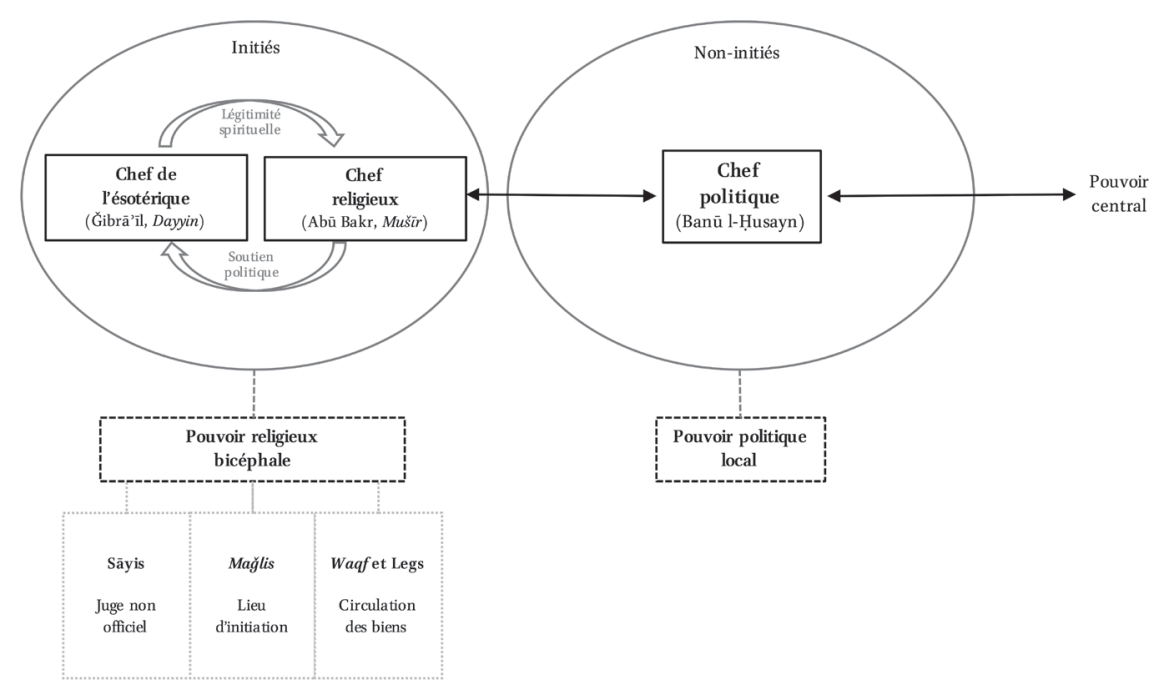

figure 3 Institutions religieuses druzes.

une ascension sociale qu'après être rentré au service d'al-Sayyid. Les sources de première main le dépeignent en fait comme son fils spirituel et lui attribuent de grandes qualités personnelles, ainsi qu'une fine connaissance des notions spirituelles ${ }^{90}$. Ainsi, tout porte à croire qu'il prit la direction spirituelle de la communauté des initiés; en d'autres termes, il en devint le chef ésotérique (dayyin) après la mort d'al-Sayyid.

Toutefois, Ğibrā'îl n'était pas le seul chef du groupe puisque la littérature de l'époque en désigne un autre, l'émir Sayf al-Dīn Abū Bakr (voir fig. 1). Ce dernier, contrairementà Ğibrā̄ 1 l, était issu de la prestigieuse famille des Banū 1-Husayn et était donc un parent biologique d'al-Sayyid ; il possédait ainsi un prestige social que ses contemporains mettent en exergue dans leurs discours $^{91}$. Mais, à l'instar de Ğibrā' 1 l, il était un grand-Disciple ayant reçu son initiation spirituelle directement d'al-Sayyid ${ }^{92}$. De plus, Abū Bakr semble avoir été un docteur en droit musulman ( 'älim, faqīh) ayant délivré des fatwas et ayant œuvré pour l'intérêt général dans sa région, en tentant de réconcilier (șulḥ) les adversaires qui se présentaient à lui ${ }^{93}$. À la différence de Ğibrā' 1 l, son action dépassait alors le cadre de la communauté des initiés, quand bien même ces derniers le désignèrent comme leur chef ( $m u s ̌ s i r)$ et que, de son côté,

$\overline{90 \quad \text { Ibid., }}$. 896-898, 933; Mir' 1 , MS Berlin, Staatsbibliothek, Ldbg 210, fol. 252v-253r.

91 Ibn Sibāț, Ta'rīh,p. 797, 809, 896; Mir '⿳亠丷, MS Berlin, Staatsbibliothek, Ldbg 210, fol. 251r-v.

92 Ibid.

93 Ibn Sibāț, Ta'rīh p. p. 848. 
il étendit leur pouvoir dans leurs villages d'origine ${ }^{94}$. Précisons que les sources ne mentionnentaucune tension entre ces deux successeurs de l'émiral-Sayyid qui opérèrent dans une bonne entente mutuelle, l'un, écrit Ibn Sibāt, ayant été un appui ('awn) de l'autre ${ }^{95}$.

L'émergence d'un pouvoir religieux bicéphale après le trépas d'al-Sayyid reflète somme toute la formation de deux institutions non officielles à la tête du groupe des initiés : l'institution du chef de l'ésotérique et celle du chef religieux. La distinction entreelles semble de prime abord ténue, mais un examen minutieux des sources de première main dans le contexte socio-politique du Garb permet de mettre en exergue leurs particularités. En effet, le magistère spiritueldeĞibrā'îlluipermit d'exercerson autoritésur ses frères de religionet d'être leur référent en matière d'ésotérisme, alors que l'émir Abū Bakr, fort de son statut social, renforça leurposition dans les villagesdu Ġarb et du Šŭf. Afin de déterminer plus précisément le rôle d'Abū Bakr, il convient de replacer le personnage historique dans son contexte familial, mais aussi dans le contexte politique local. À en croire Mir ${ }^{\wedge} \overline{1}$, son nom était parmi les plus illustres de son temps ${ }^{96}$. En fait, l'éminence sociale d'Abū Bakr faisait résolument sa renommée: songrand-père était célèbre et portait le titre honorifique de grand-Émir; et son père était proche du pouvoir mamelouk et aurait, selon Ibn Sibāt, accompli de grandes actions ${ }^{97}$. Les Banū 1-Husayn étaient par ailleurs les maîtres $\mathrm{du}$ Ğarb $^{98}$; ils gouvernaient en effet la région au nom du pouvoir central et y possédaientles plus grands iqț̄à 's. Ainsi, AbūBakrappartenait, de fait, àl'élite politique du Ġarb et, par conséquent, possédait une certaine autorité temporelle qui s'avère avoirété propice aux initiés druzes ; autrement dit, il servit de trait d'union entre ce groupe et le pouvoir local.

Il faut ainsi conclureàl'existence dans le Ġarbd'un pouvoir politique, celui des Banū l-Ḥusayn, ayant servi de terreau pour la formation d'une école juridique druze, le sayyidisme. Issu de cette famille, l'émir al-Sayyid se distingua des autres savants druzes par son prestige social et réussit à exercer son magistère spirituel sur un groupe de disciples, les Sayyidiens, qui lui furent fidèles et qui pérennisèrent son enseignement. La formation de ce groupe et sa transformation en un parti, que les sources appellent le «parti de l'émir», furentégalement possibles grâce à un important soutien financier: l'émir Sayf al-Dīn, maître spirituel, constitua en waqf ses biens au profit de son disciple

\footnotetext{
$\overline{94 \quad \text { Ibid., }}$ p. 896.

95 Ibid.

96 Mir '̄ī, MS Berlin, Staatsbibliothek, Ldbg 210, fol. $251 \mathrm{r}$.

97 Ibn Sibāt, Ta'rīh, p. 797, 809.

98 Sur le pouvoir local des Banū l-Ḥusayn, voir Halawi, Le druzisme au IXe/XVe siècle, p. 490-505.
} 
et parent, l'émir al-Sayyid, lequel légua à son tour sa fortune à ses principaux disciples sous forme de waqfs et de donations charitables. Les Sayyidiens développèrent ainsi au fil du temps un réseau d'influence dans les villages du Ġarb et du Šŭf, où ils transmirent la vision théologico-juridique de leur maitre. Celle-ci se présentait alors sous forme d'une doctrine personnelle ayant été fidèlement transmise par une poignée de disciples-savants, mais tout porte à croire qu' existaient en parallèle d'autres interprétations personnelles de la religion et du droit. Toutefois, l'élaborationd'un véritable systèmejuridique que décrivent les traités inédits de droit druze (les Šarḥayn) eut lieu après le trépas d'al-Sayyid et fut sans doutel'œuvre des Sayyidiens et de leurs continuateurs. C'est donc dans ce contex te qu'émergèrent le mad ha $a b$ ou école théologico-juridique druze, mais aussi les premières institutions religieuses.

Ceci dit, pourquoi le contexte sayyidien apparaît-il comme le seul lieu de production d'un savoir druze, alors que d'autres grandes familles druzes, notamment les Banū Abī Lam ', originaires du Kisrawān, détenaient également à cette époque un pouvoir politique fort au niveau local ? De quelle manière et sous quelle autorité les divergences doctrinales entre savants druzes auraient-elles été gommées, si bien que le madh $a b$ druze se présente aujourd'hui sous formed'unevision uniqueadoptée sanséquivoque par tous les religieux? Jusqu'à quel point les doctrines juridiques musulmanes majoritaires dans la Syrie prémoderne et moderne ont-elles influencé l'élaboration et l'évolution du droit druze? Et, enfin, comment le contexte socio-culturel de la constitutiond'unsystèmethéologico-juridiquedruzepourrait-ilnouséclairersurcelui de la canonisation de la Hikma? Comme on le voit au terme de cette nouvelle lecture de l'histoire du druzisme prémoderne, bien des questions demeurent en suspens. 